\title{
Cyclic deformation and fatigue of extruded AZ31B magnesium alloy under different strain ratios
}

\author{
Ying Xiong a , Qin Yu ${ }^{\mathrm{b}}$, Yanyao Jiang ${ }^{\mathrm{b}, *}$ \\ ${ }^{a}$ Zhejiang University of Technology, College of Mechanical Engineering, Hangzhou, \\ Zhejiang 310032, China \\ ${ }^{\mathrm{b}}$ University of Nevada, Reno, Department of Mechanical Engineering, Reno, NV 89557, USA, \\ Phone 775-784-4510, Fax 775-784-1701, E-Mail yjiang@unr.edu
}

*To whom correspondence should be addressed.

\begin{abstract}
Cyclic deformation and fatigue behavior of extruded AZ31B magnesium (Mg) alloy were investigated under strain-controlled loading along the extrusion direction at different strain amplitudes with three strain ratios $\left(R_{\varepsilon}=0,-1,-\infty\right)$. With a strain ratio of $R_{\varepsilon}=-\infty$, partial twinning-partial detwinning occurs at all strain amplitudes, leading to accumulation of deformation twins as the loading cycle is increased. With strain ratios being $R_{\varepsilon}=0$ and -1 , partial twinning-complete detwinning is the cyclic deformation mechanism when the strain amplitude is higher than $0.35 \%$. At a strain amplitude lower than $0.35 \%$, dominant cyclic deformation mechanism is dislocation slips irrespective of the strain ratio. Compared with the cases of $R_{\varepsilon}=0$ and $R_{\varepsilon}=-1$, stronger cyclic hardening is exhibited at all the investigated strain amplitudes for $R_{\varepsilon}=-\infty$. Fatigue fracture surfaces show regions with lamellar-like and dimplelike features. Lamellar-like feature existing in the crack initiation and stable propagation region are mainly due to twinning-detwinning during cyclic deformation. The dimple-like feature formed in the unstable crack propagation and final rupture region mainly arises from severe intragranular plastic deformation by dislocation slips. At the same strain amplitude, the lamellar-like traces become more aggravated with a lower stain ratio. The strain-fatigue life curves exhibit a distinguishable kink at strain ratios $R_{\varepsilon}=-\infty,-1$ and 0 . The fatigue life with $R_{\varepsilon}=-\infty$ shows the highest and that with $R_{\varepsilon}=0$ is the lowest at the same strain amplitude. The Smith-WatsonTopper (SWT) fatigue criteria can correlate well the fatigue experiments of AZ31B Mg alloy under different strain ratios.
\end{abstract}

Keywords: Magnesium alloy; Twinning; Strain ratio effect; Fracture; Fatigue life 


\section{Introduction}

The transportation industry is getting more interests in innovative approaches to improving fuel efficiency to reduce greenhouse gas emission. An effective way is to decrease the vehicle weight by using lightweight structural materials. Magnesium $(\mathrm{Mg})$ alloy is an attractive candidate due to its high strength-to-weight ratio. To be applied as structural parts in service, $\mathrm{Mg}$ alloys inevitably undergo cyclic loading and fatigue failure may occur. Accordingly, it is necessary to study the cyclic deformation and fatigue resistance of $\mathrm{Mg}$ alloys for safety and reliability purposes.

Wrought Mg alloys do not have casting defects and have favorable mechanical properties as compared to their casting counterparts. Wrought Mg alloys with a hexagonal close-packed (HCP) crystal structure have strong basal textures formed by rolling and extrusion, i.e., the $c$-axes of most grains are perpendicular to the extrusion or rolling direction. There have been a number of studies on low-cycle fatigue (LCF) behavior of extruded Mg alloys, such as AZ31/AZ31B [1-26], AZ61/AZ61A [27-34], AM30 [35-38], AM50 [39], ZK60 [40-46], and AZ91D [47]. These extruded $\mathrm{Mg}$ alloys exhibit common characteristics of cyclic deformation. Cyclic stress-strain response shows obvious shape asymmetry between the tensile and compressive reversals. The alternation of twinning and detwinning plays a critical role on the cyclic deformation of $\mathrm{Mg}$ alloys. It has been established that the twinning-detwinning process dominates plastic deformation at higher strain amplitudes, whereas dislocation slips dominate the plastic deformation at lower strain amplitudes [26-27,39]. Experimental investigations reveal that the fatigue resistance and cyclic response are affected by various factors, including loading path [17,22,30-31], strain rate [9,35], microstructure and texture [3,10-14,16,19-20,24,28,32,45], and stress ratio [6,34,43]. However, most studies concerning the fatigue behavior of $\mathrm{Mg}$ alloys are carried out by applying symmetric cyclic loading (fully reversed strain- or stress-controlled). Investigations dedicated to studying the effect of asymmetric strain-controlled loading on fatigue properties of extruded $\mathrm{Mg}$ alloys are limited. Begum et al. [9,35] investigated the effect of strain ratio $\left(R_{\varepsilon}=-2 \sim 5\right)$ on fatigue properties of extruded AZ31 and AM30 Mg alloys at a strain amplitude of $0.4 \%$. It was found that stronger cyclic strain hardening easily occurred at lower strain ratios. Geng et al. [23] investigated the LCF behavior of extruded AZ31B Mg alloy at $R_{\varepsilon}=-\infty$. The study revealed that cyclic plastic deformation at low strain amplitude was dominated by dislocation slips while the twinning-detwinning was the dominant deformation mode under high strain amplitudes. Yu et al. [34] studied the effect of strain ratio $\left(R_{\varepsilon}=-\infty,-1,0\right)$ on cyclic deformation and fatigue of extruded AZ61 A Mg alloy and found that a distinguishable kink existed in the strain-fatigue life curve obtained from experiments with different strain ratios. The decreased cyclic hardening capacity at higher strain ratios were due to less twinning-detwinning activities [34]. 
The current work aims to further investigate the cyclic deformation and fatigue behavior of extruded AZ31B Mg alloy at a wide range of strain amplitudes $(0.2 \% \sim 2 \%)$ with three strain ratios $\left(R_{\varepsilon}=0,-1,-\infty\right)$. The cyclic stress-strain response, variation of stress responses, fatigue life, and fractography characteristics are presented with an emphasis on the influence of strain ratios and strain amplitudes. Based on the experimental observations, the mechanisms of cyclic deformation and fatigue associated with different strain ratios are discussed. The Smith-WatsonTopper (SWT) fatigue criterion was evaluated for its capability to predict the fatigue lives of the $\mathrm{Mg}$ alloy tested at different strain ratios.

\section{Material and experiments}

\subsection{Material and specimen}

The material used in the present study is an extruded AZ31B $(2.5-3.5 \mathrm{wt} \% \mathrm{Al}, 0.7-1.3 \mathrm{wt} \% \mathrm{Zn}$, $\mathrm{Mg}$ balance) $\mathrm{Mg}$ alloy. Static mechanical properties of the material are shown in Table 1 [22]. The dog-bone shaped plate testing specimens for fatigue experiments were machined from the material bar with a diameter of $46 \mathrm{~mm}$ along its extrusion direction (Fig. 1). The geometry and dimensions of the testing specimen are shown in Fig. 1a. The axial direction of the specimen is aligned parallel to the extrusion direction of the material bar. Three layers of specimens were obtained along the extrusion direction with their cross sections denoted by symbols I, II and III from the outer layer to the inner layer (Fig. 1b). Before mechanical testing, the flat surfaces of the testing specimen were grounded and polished by using silicon carbide papers with grit No. ranging from 400 up to 1,200 .

Table 1 Static material properties of extruded AZ31B Mg alloy [22]

\begin{tabular}{rl}
\hline Elasticity modulus, $E$ & $44.8 \mathrm{GPa}$ \\
$0.2 \%$-offset yield stress in tension, $\sigma_{y t}$ & $244 \mathrm{MPa}$ \\
$0.2 \%$-offset yield stress in compression, $\sigma_{y c}$ & $151 \mathrm{MPa}$ \\
Ultimate strength under tension, $S_{u t}$ & $298 \mathrm{MPa}$ \\
Ultimate strength under compression, $S_{u c}$ & $417 \mathrm{MPa}$ \\
Fracture stress under tension, $\sigma_{f t}$ & $338 \mathrm{MPa}$ \\
Elongation under tension, $e_{f t}$ & 0.105 \\
Elongation under compression, $e_{f c}$ & 0.093 \\
Reduction in area under tension, $R A$ & $0.12 \%$ \\
\hline
\end{tabular}




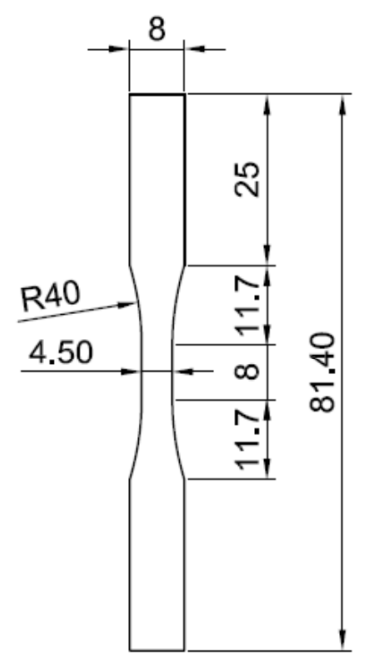

thickness $=4.0$

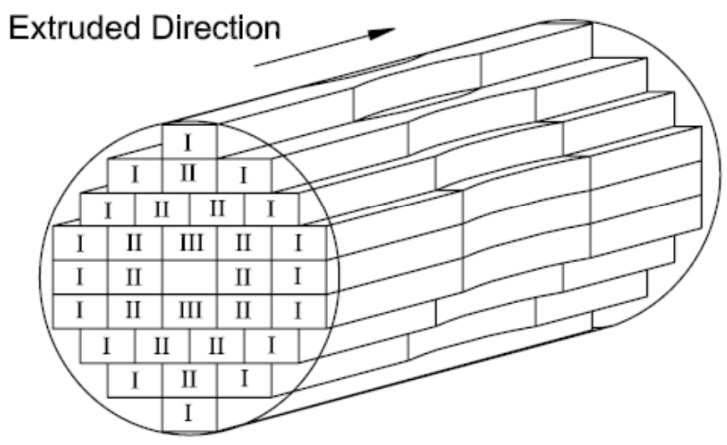

(a)

(b)

Fig. 1. Geometry and dimensions of extruded AZ31B Mg alloy specimens (Unit: mm)

Metallographic samples were cut from the original material. Three orthotropic sections which are perpendicular to the extrusion direction (ED), tangential direction (TD), and normal direction (ND) were grounded by silicon carbide paper with grit No. up to 1,200, followed by mechanical polishing by using $6 \mu \mathrm{m}$ and $1 \mu \mathrm{m}$ diamond polycrystalline suspension pastes. The polished surfaces were etched with the Acetic-Picral solution $(10 \mathrm{~mL}$ acetic acid, $4.2 \mathrm{~g}$ picric acid, $10 \mathrm{~mL}$ distilled water, and $70 \mathrm{~mL}$ ethanol (95 pct)). Fig. 2a shows a three-dimensional stereography of the optical microstructure. An inhomogeneous microstructure composed of both large and small equiaxed grains was observed on the ND-TD plane. On the planes perpendicular to the TD and ND directions, grains were elongated due to the extrusion process and a fibrous grain structure was resulted. The average sizes for the large and small grains were approximately $50 \mu \mathrm{m}$ and $8 \mu \mathrm{m}$, respectively. No initial twins were detected in the undeformed state. The microstructure and the pole figures obtained by electron backscattered diffraction (EBSD) scanning on the ED-ND plane are shown in Figs. 2b and 2c, respectively. The (0002) and $\{10 \overline{1} 0\}$ pole figures show that the material has a typical basal texture where the $c$-axes of a majority of grains are approximately perpendicular to the ED direction of the extrusion bar. 
(a)

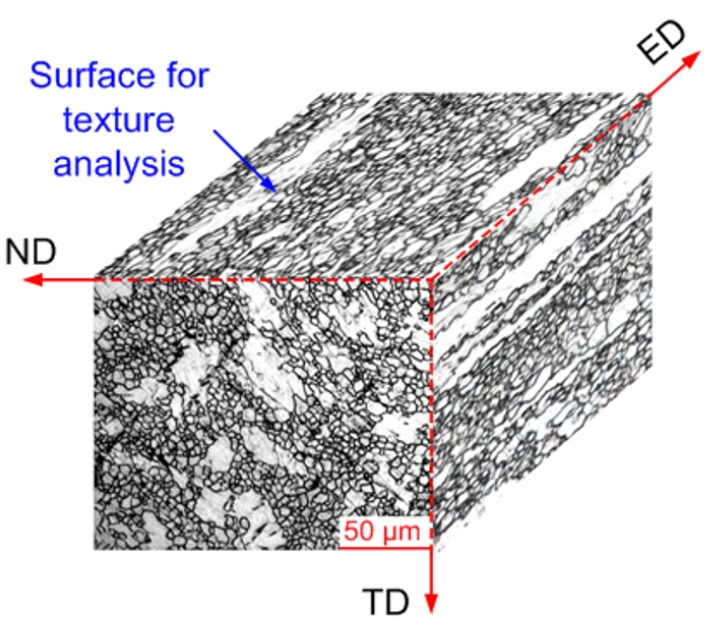

(b)

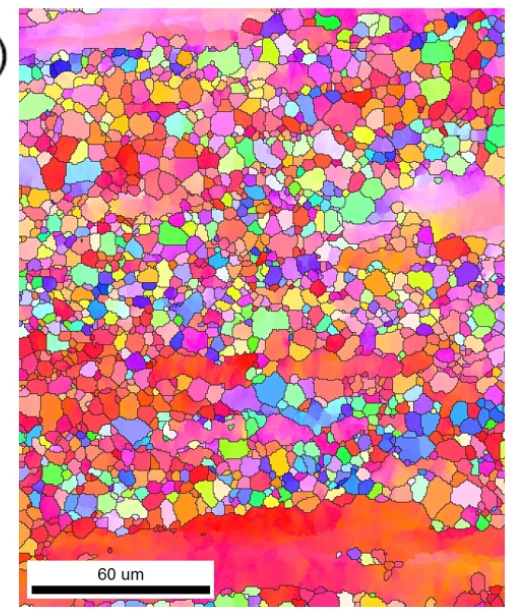

(c)
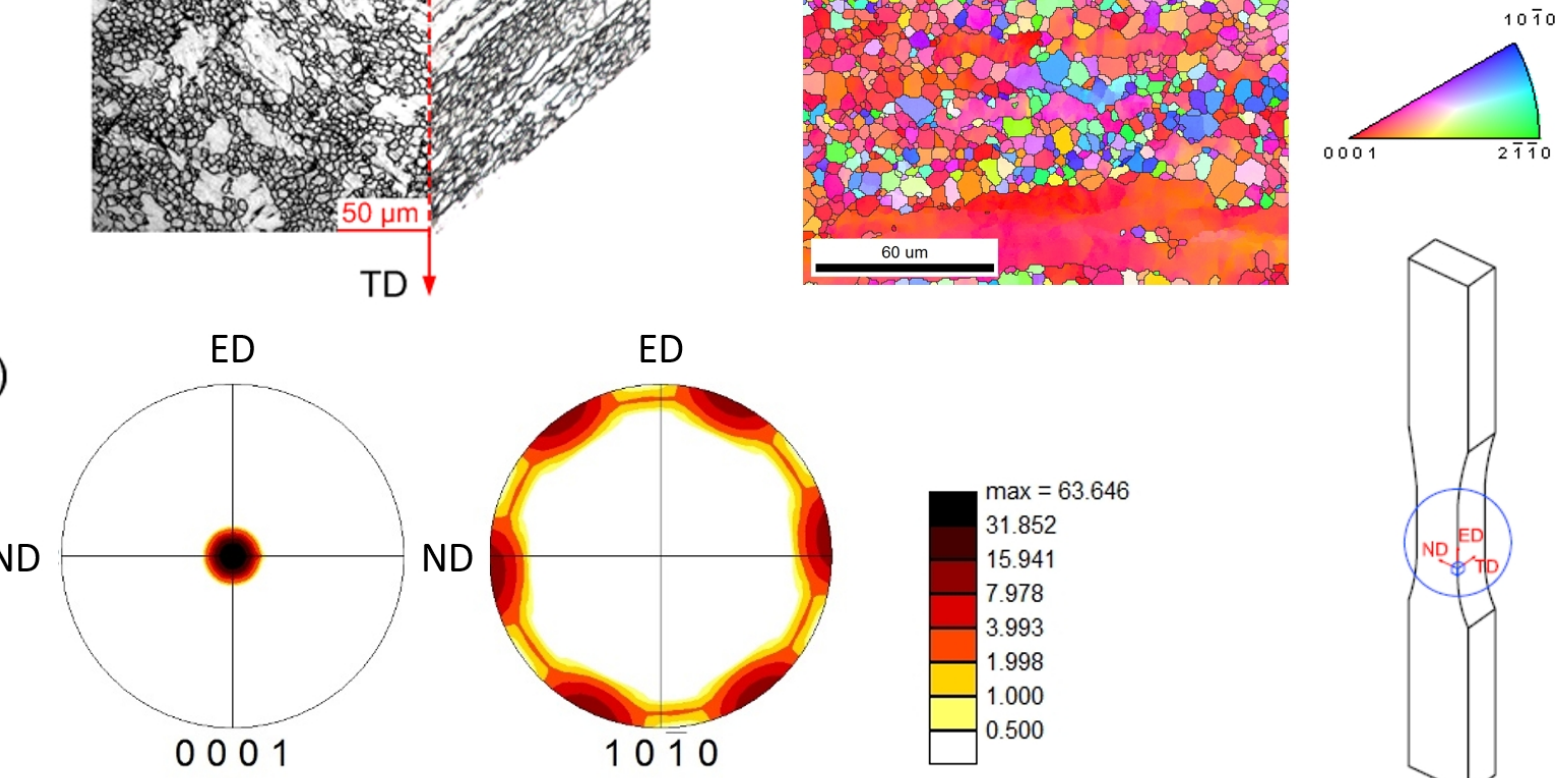

Fig. 2. Initial microstructure and texture of the extruded AZ31B Mg alloy: (a) three-dimensional optical stereography, (b) crystal orientation map, and (c) (0002) and $\{10 \overline{1} 0\}$ pole figures.

\subsection{Experiments and microscopy}

Fatigue tests were conducted at three strain ratios $\left(R_{\varepsilon}=0,-1,-\infty\right)$ using a computerized servohydraulic material testing system at room temperature. A sinusoidal wave form was applied. Strain amplitudes ranged from 0.002 to 0.02 and the corresponding testing frequencies were from $10 \mathrm{~Hz}$ to $0.1 \mathrm{~Hz}$. The load and engineering strain outputs were recorded by the computer data acquisition system. For each loading cycle, a minimum of 200 data points were recorded. Each fatigue specimen was tested until the specimen was completely fractured into two pieces. The fatigue life was determined corresponding to the moment when the stress amplitude in a loading cycle displayed a $5 \%$ reduction from the stabilized value. The loading conditions and all the fatigue results are listed in Table 2. The stabilized stress and strain values were taken from the stress-strain hysteresis loop at approximately $50 \%$ of the fatigue life. The degree of tension twins remained in selected fatigue-failed samples was evaluated by analyzing X-ray diffraction (XRD) pattern scanned on the ED-ND plane. Fracture surface of the separated specimen was examined using scanning electron microscopy (SEM) (JEOL JSM-6510). 
Table 2 Fatigue results for extruded AZ31B obtained from strain-controlled fatigue experiments with different $R_{\varepsilon}$-ratios

\begin{tabular}{|c|c|c|c|c|c|c|c|}
\hline Spec ID & $\begin{array}{c}\text { Layer } \\
\text { No. }\end{array}$ & $R_{\varepsilon}$ & $\begin{array}{c}f \\
(\mathrm{~Hz})\end{array}$ & $\begin{array}{c}\Delta \varepsilon / 2 \\
(\%)\end{array}$ & $\begin{array}{c}\sigma_{\mathrm{m}} \\
(\mathrm{MPa})\end{array}$ & $\begin{array}{c}\Delta \sigma / 2 \\
(\mathrm{MPa})\end{array}$ & $\begin{array}{c}N_{\mathrm{f}} \\
\text { (cycle) }\end{array}$ \\
\hline 31BPE1321 & II & -1 & 0.2 & 2 & 34.9 & 220.7 & 200 \\
\hline 31BPE1522-3 & II & -1 & 0.15 & 1.5 & 48.6 & 223.1 & 310 \\
\hline 31BPE2424 & II & -1 & 0.25 & 1 & 51.5 & 224.9 & 700 \\
\hline 31BPE1314 & I & -1 & 0.5 & 0.75 & 52.2 & 219.9 & 970 \\
\hline 31BPE1422 & II & -1 & $0.2 / 0.75$ & 0.6 & 42.7 & 201.5 & 1,980 \\
\hline 31BPE1424 & II & -1 & 0.75 & 0.55 & 45.0 & 193.6 & 2,780 \\
\hline 31BPE1222 & II & -1 & 1 & 0.5 & 37.0 & 191.7 & 3,920 \\
\hline 31BPE1421 & II & -1 & 1.25 & 0.45 & 29.3 & 178.3 & 7,260 \\
\hline 31BPE1214 & I & -1 & 1.5 & 0.4 & 4.5 & 165.0 & 9,720 \\
\hline 31BPE1423 & II & -1 & $0.25 / 2.5$ & 0.35 & 12.7 & 138.9 & 22,060 \\
\hline 31BPE1324 & II & -1 & $2 / 5$ & 0.32 & 0.1 & 130.4 & 48,000 \\
\hline 31BPE1521 & II & -1 & 2 & 0.3 & 3.4 & 136.3 & 100,930 \\
\hline 31BPE 1323 & II & -1 & $2 / 10$ & 0.28 & -2.6 & 122.8 & 313,000 \\
\hline 31BPE1522 & II & -1 & $2 / 6$ & 0.25 & -0.2 & 107.8 & $>1,022,500$ \\
\hline 31BPE2423 & II & 0 & 0.15 & 1.5 & 48.6 & 223.4 & 274 \\
\hline 31BPE2313 & I & 0 & 0.2 & 1 & 41.5 & 226.0 & 418 \\
\hline 31BPE2411 & I & 0 & 0.5 & 0.75 & 50.0 & 224.4 & 1,040 \\
\hline 31BPE2414 & I & 0 & 0.4 & 0.6 & 38.8 & 214.8 & 1,640 \\
\hline 31BPE2314 & I & 0 & 1 & 0.5 & 38.3 & 197.0 & 4,240 \\
\hline 31BPE2413 & I & 0 & 1.5 & 0.4 & 49.5 & 167.3 & 7,480 \\
\hline $31 \mathrm{BPE} 2315$ & I & 0 & 2.5 & 0.35 & 67.4 & 152.0 & 10,900 \\
\hline 31BPE2442 & III & 0 & $0.5 / 2 / 3$ & 0.3 & 70.5 & 127.6 & 17,600 \\
\hline 31BPE2522 & II & 0 & $2.5 / 4$ & 0.25 & 71.3 & 117.3 & 104,620 \\
\hline 31BPE1441 & III & 0 & $2 / 10$ & 0.225 & 77.5 & 104.8 & 252,900 \\
\hline 31BPE2321 & II & 0 & 4 & 0.2 & 71.2 & 93.1 & $>597,120$ \\
\hline 31BPE2111 & I & $-\infty$ & 0.1 & 1 & 25.4 & 215.3 & 690 \\
\hline 31BPE2323 & II & $-\infty$ & 0.4 & 0.75 & 43.8 & 210.4 & 1,480 \\
\hline 31BPE2322 & II & $-\infty$ & 0.75 & 0.6 & 29.0 & 192.8 & 3,440 \\
\hline 31BPE2421 & II & $-\infty$ & 1 & 0.5 & 24.0 & 174.5 & 5,100 \\
\hline 31BPE2511 & I & $-\infty$ & $1 / 2$ & 0.4 & -13.8 & 151.5 & 10,100 \\
\hline 31BPE2441 & III & $-\infty$ & $0.5 / 1.5$ & 0.38 & -1.3 & 150.0 & 38,340 \\
\hline 31BPE2521 & II & $-\infty$ & $1.5 / 2.5$ & 0.37 & -2.0 & 143.9 & 30,800 \\
\hline 31BPE2422 & II & $-\infty$ & $1.5 / 2$ & 0.35 & -7.7 & 143.5 & 48,500 \\
\hline 31BPE2512 & I & $-\infty$ & $2 / 4 / 6$ & 0.32 & -20.5 & 141.2 & 161,500 \\
\hline 31BPE2221 & II & $-\infty$ & 3 & 0.3 & -27.4 & 134.5 & 555,200 \\
\hline 31BPE2423 & II & $-\infty$ & $2 / 4 / 6 / 10$ & 0.25 & -37.3 & 114.6 & $>988,000$ \\
\hline
\end{tabular}




\section{Results and discussion}

\subsection{Cyclic stress-strain response}

Three strain amplitudes are selected to analyze the influence of strain ratio on the cyclic deformation behavior. Figs. 3 shows the evolution of typical stress-strain hysteresis loops at strain amplitude of $1.0 \%, 0.5 \%$, and $0.3 \%$, respectively, with three strain ratios. The stress-strain hysteresis loops of the initial ten loading cycles, the quarter loading cycle, and the half-life loading cycle were plotted.

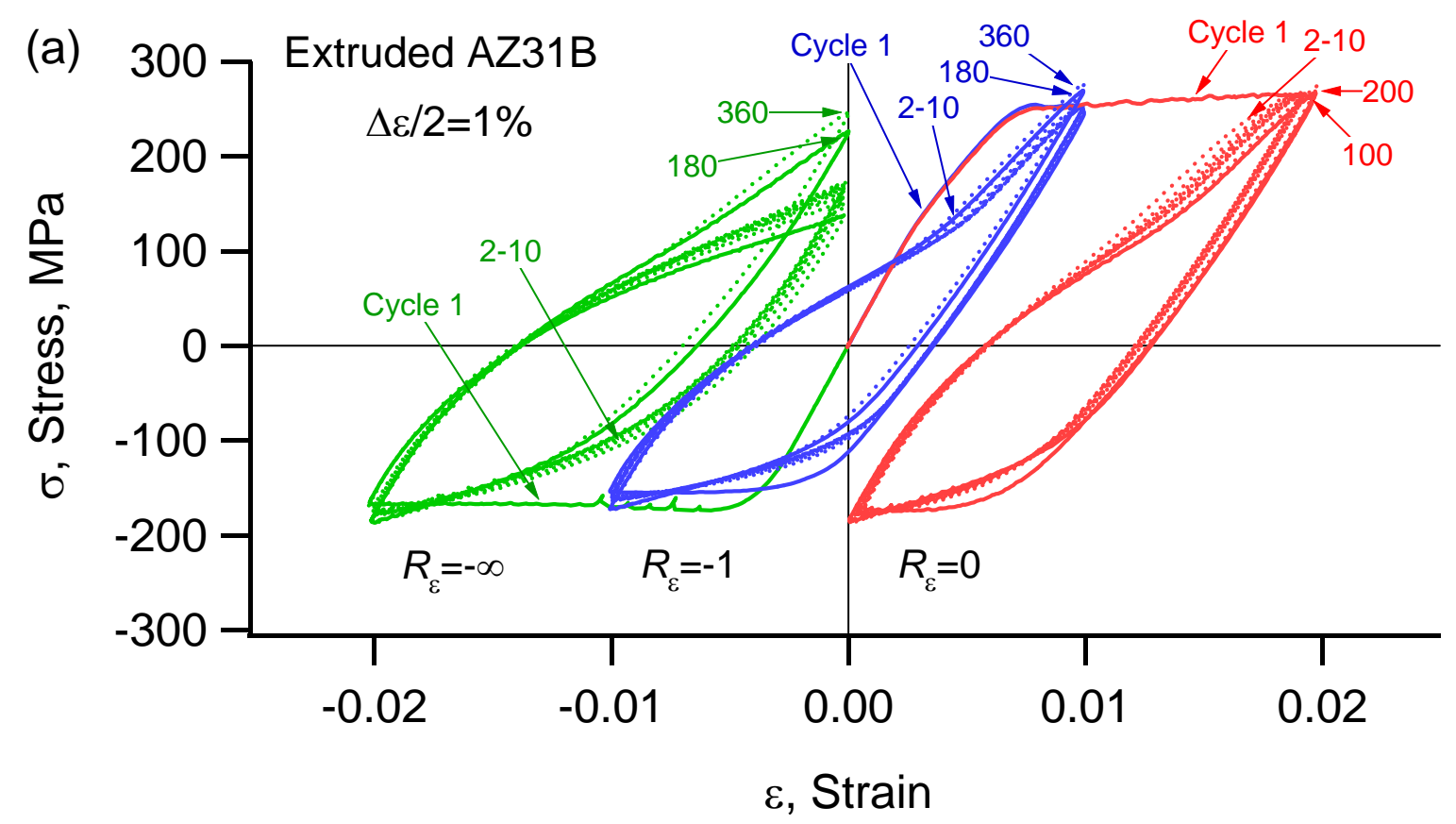




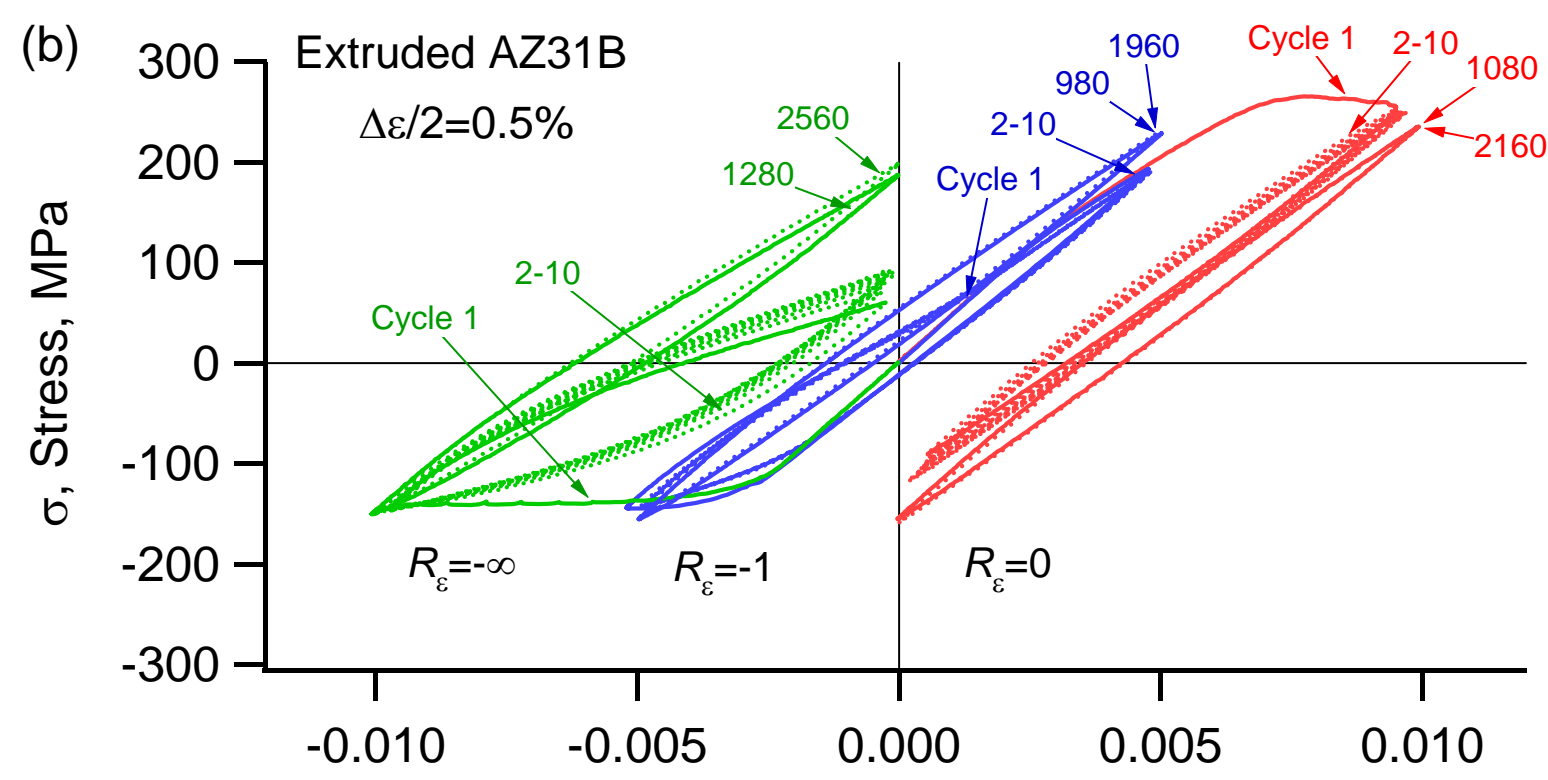

\section{$\varepsilon$, Strain}

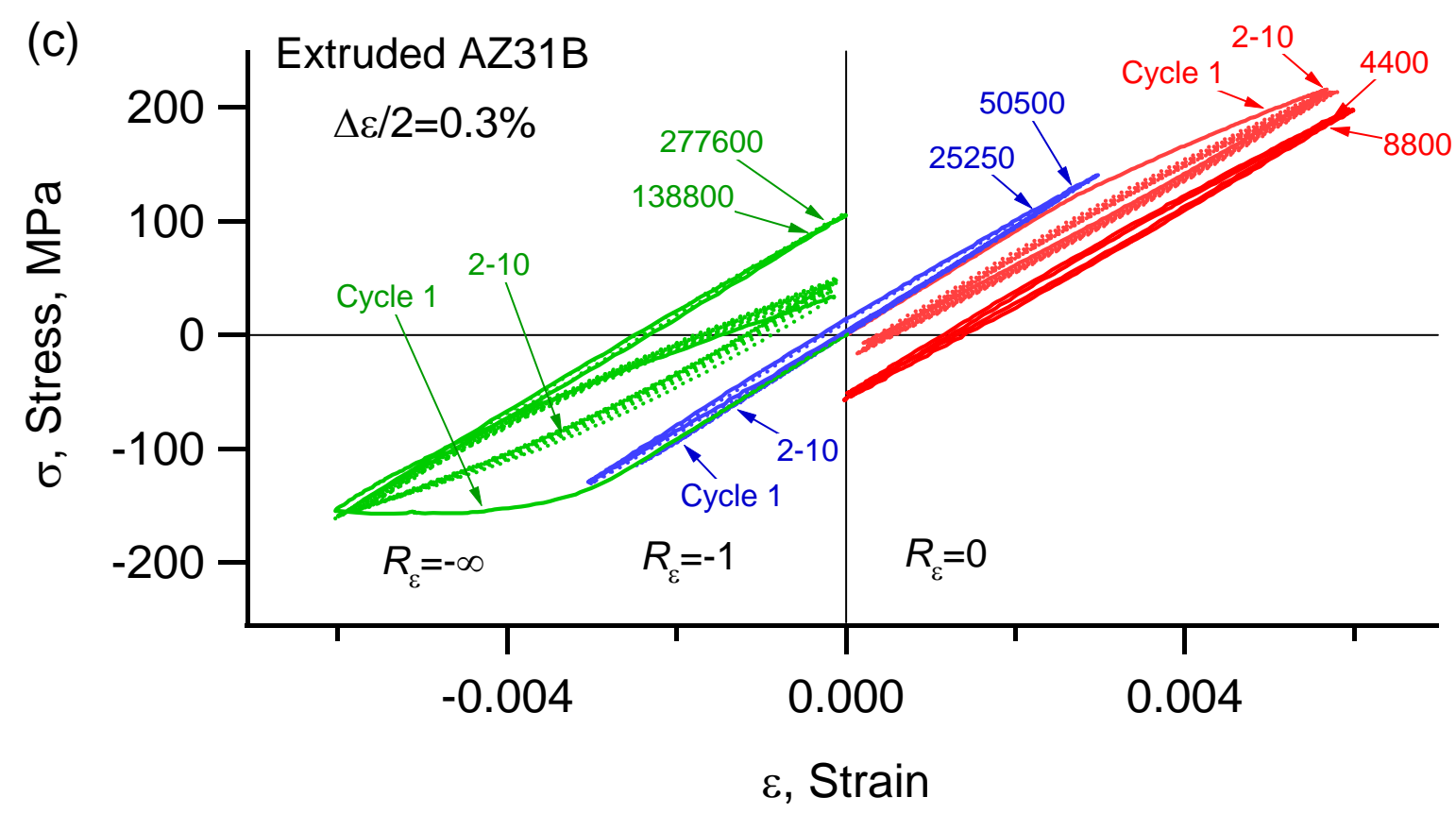

Fig. 3. Stress-strain hysteresis loops with different strain ratios at strain amplitudes of (a) $\Delta \varepsilon / 2=1 \%$, (b) $\Delta \varepsilon / 2=0.5 \%$, and (c) $\Delta \varepsilon / 2=0.3 \%$.

With $R_{\varepsilon}=-1$ at the strain amplitude of $1 \%$ (Fig. 3a), the initial tensile loading phase displays the same deformation behavior as exhibited in the monotonic tension experiment [22]. The compressive peak stress $(-154 \mathrm{MPa})$ and the tensile peak stress $(251 \mathrm{MPa})$ in the first loading cycle are higher than the monotonic yielding stresses $-151 \mathrm{MPa}$ in compression and $244 \mathrm{MPa}$ in tension, respectively. As the $c$-axis of most grains is perpendicular to the extrusion direction 
(loading direction) before mechanical loading, $\{10 \overline{1} 2\}$ tension twinning can occur in the compressive reversal and detwinning is expected in the subsequent tensile reversal $[6,8]$. Owing to a relatively short compressive strain range at $\Delta \varepsilon / 2=1 \%$, the twinning capacity is far beyond exhaustion during the compressive loading. Accordingly, the compressive reversal only shows a concave-up shape, whereas the tensile reversal exhibits a sigmoidal shape, where detwinning dominates the concave-down portion and dislocation slips dominate the concave-up portion. This type of twinning-detwinning behavior is referred to as "partial twining-complete detwinning" [42-44]. Previous research has shown that cyclic hardening is mainly attributed to the increased dislocation densities as well as the accumulated residual twin boundaries [2,7,40-41,48]. At a strain amplitude of $0.5 \%$ (Fig. 3b), the maximum tensile peak stress (approximately $186 \mathrm{MPa}$ ) is lower than the monotonic tensile yield stress $(244 \mathrm{MPa})$, which is not sufficient to activate the macroscopic yielding that is caused by the activation of non-basal slips. However, the compression peak stress (approximately $145 \mathrm{MPa}$ ) is close to the monotonic compressive yield stress $(151 \mathrm{MPa})$, indicating that tension twins may be formulated at local favorable-oriented grains. The stress-strain hysteresis loops show an asymmetric sigmoidal shape, in particular during the initial stage of the cyclic deformation. With the advance of cyclic deformation, tensile and compressive peak stresses are increased. After approximately 100 loading cycles, the asymmetric shape of the hysteresis loop gradually transits to a symmetric shape. This is likely due to the significant reduction of twinning-detwinning activities [42]. In brief, the dominant deformation mechanism at the strain amplitude of $0.5 \%$ remains to be "partial twining/complete detwinning" [44]. When the strain amplitude is decreased to $0.3 \%$ (Fig. 3c), the stress-strain hysteresis loops keep a perfectly symmetric shape during all the loading cycles, indicating that dislocation slips are dominantly operative under both tension and compression reversals.

Cyclic deformation behavior at the strain amplitude of $1 \%$ (Fig. 3a) with $R_{\varepsilon}=0$ is basically the same as that at $R_{\varepsilon}=-1$. At the strain amplitude of $0.5 \%$, the compressive peak stress in the initial several loading cycles does not reach the monotonic compressive yield stress. With increasing loading cycles, the compressive peak stress slightly exceeds the monotonic compressive yield stress due to the multiplied dislocation densities. Local $\{10 \overline{1} 2\}$ tension twins might be formulated during the subsequent loading cycles. Unlike the $R_{\varepsilon}=-1$ case, the tensile peak stress gradually decreases with increasing loading cycles, showing a stress relaxation phenomenon. After approximately 500 cycles, the evolution of hysteresis loops with respect to the number of loading cycles is very similar to that at the strain amplitude of $0.5 \%$ with $R_{\varepsilon}=-1$ (Fig. $3 \mathrm{~b}$ ). When the strain amplitude is decreased to $0.3 \%$, due to the dominant deformation mode by dislocations slips, perfect symmetry is exhibited in the shape of the stress-strain hysteresis loops. As the loading cycle is increased, inelastic deformation is detectable with insignificant cycle hardening. 
With $R_{\varepsilon}=-\infty$ at the strain amplitude of $1 \%$ (Fig. 3a), the compressive peak stress (165 MPa) in the initial quarter loading cycle exceeds the monotonic compressive yield stress, which obviously activates tension twinning. As shown in Fig. 3a, at the end of tensile reversal in the initial several loading cycles, detwinning did not finish completely. This microscopic process is referred to as "partial twinning-partial detwinning." Macroscopically, the tensile reversal shows a concave-down shape. As the loading cycle is increased, twins can be accumulated rapidly as a result of the repeated "partial twinning-partial detwinning" process. More interestingly, the concave-down tensile reversal gradually changes to a sigmodal shape and shows an inflection point. This shape transformation indicates that detwinning during the initial portion of tensile reversal gradually approaches exhaustion and dislocation slips operate as the dominant mechanism during the later portion. The shape transformation results in a rapid increase in the tensile peak stress and an aggravated asymmetric shape of the stress-strain hysteresis loops. As a consequence, significant cyclic hardening is observed in the later stage of the cyclic deformation. When the strain amplitude decreases to $0.5 \%$ and $0.3 \%$ (Figs. $3 \mathrm{~b}$ and $3 \mathrm{c}$ ), the volume fraction of deformation twin induced during the compressive reversal is lower than that at the strain amplitude of $1 \%$. Correspondingly, the increasing of tensile peak stress caused by the accumulation of twins is mitigated. As the loading cycle is increased, the asymmetry of the stress-strain hysteresis loops is reduced. In the meantime, the plastic strain range accommodated during a loading cycle is shortened. A careful examination of the hysteresis loops shows that a shape difference persistently exists between the upper branch and the lower branch. This observation suggests that partial twinning-partial detwinning consistently acts as a cyclic deformation mechanism even at small strain amplitudes with $R_{\varepsilon}=-\infty$. This is different from the loading cases of a small strain amplitude with $R_{\varepsilon}=0$ and -1 where dislocation slips dominate the cyclic plastic deformation. 

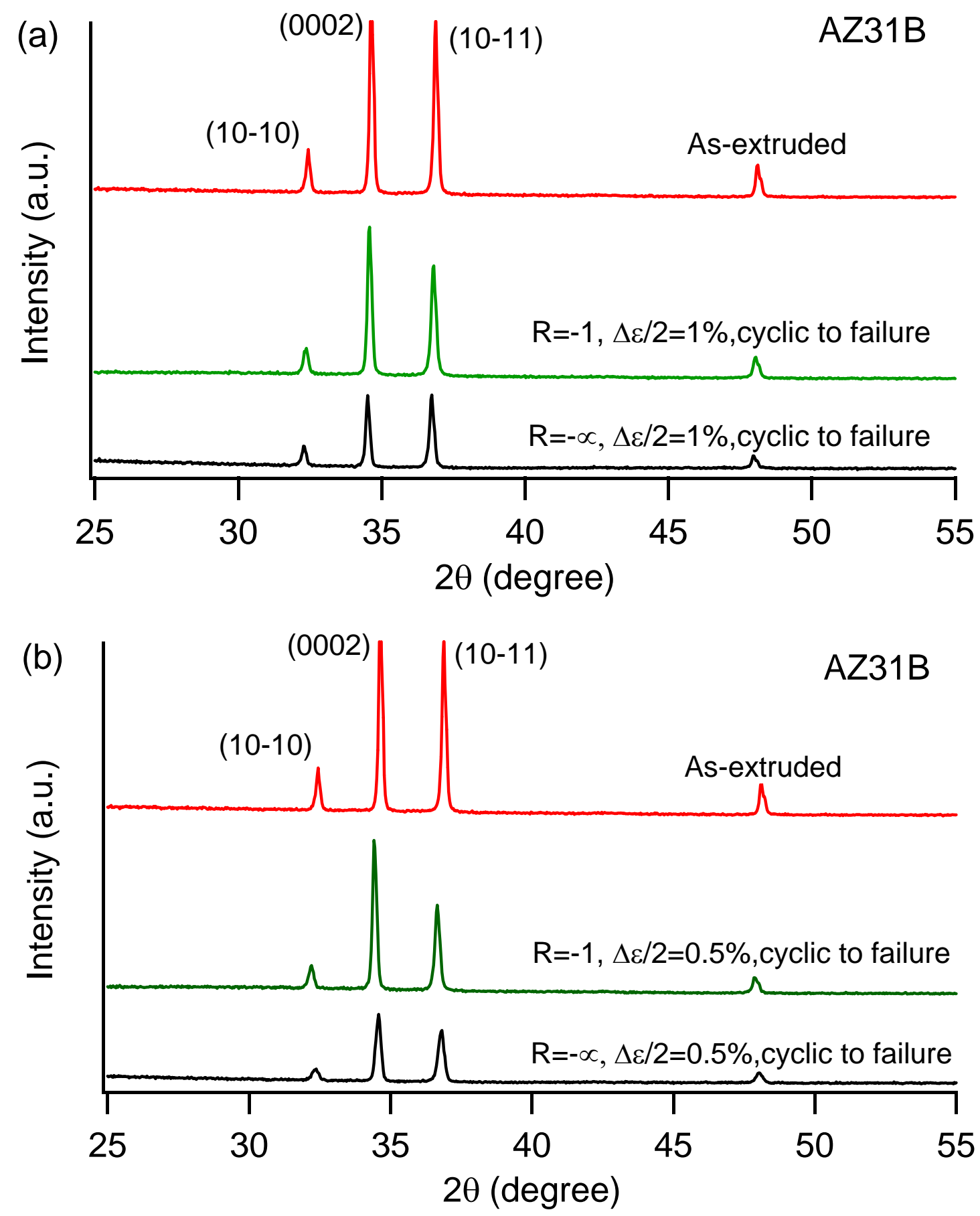

Fig. 4. X-ray diffraction (XRD) patterns scanned on the ED-ND plane of the fatigue-failed specimens with different strain ratios at strain amplitudes of (a) $\Delta \varepsilon / 2=1 \%$ (b) and $\Delta \varepsilon / 2=0.5 \%$. 


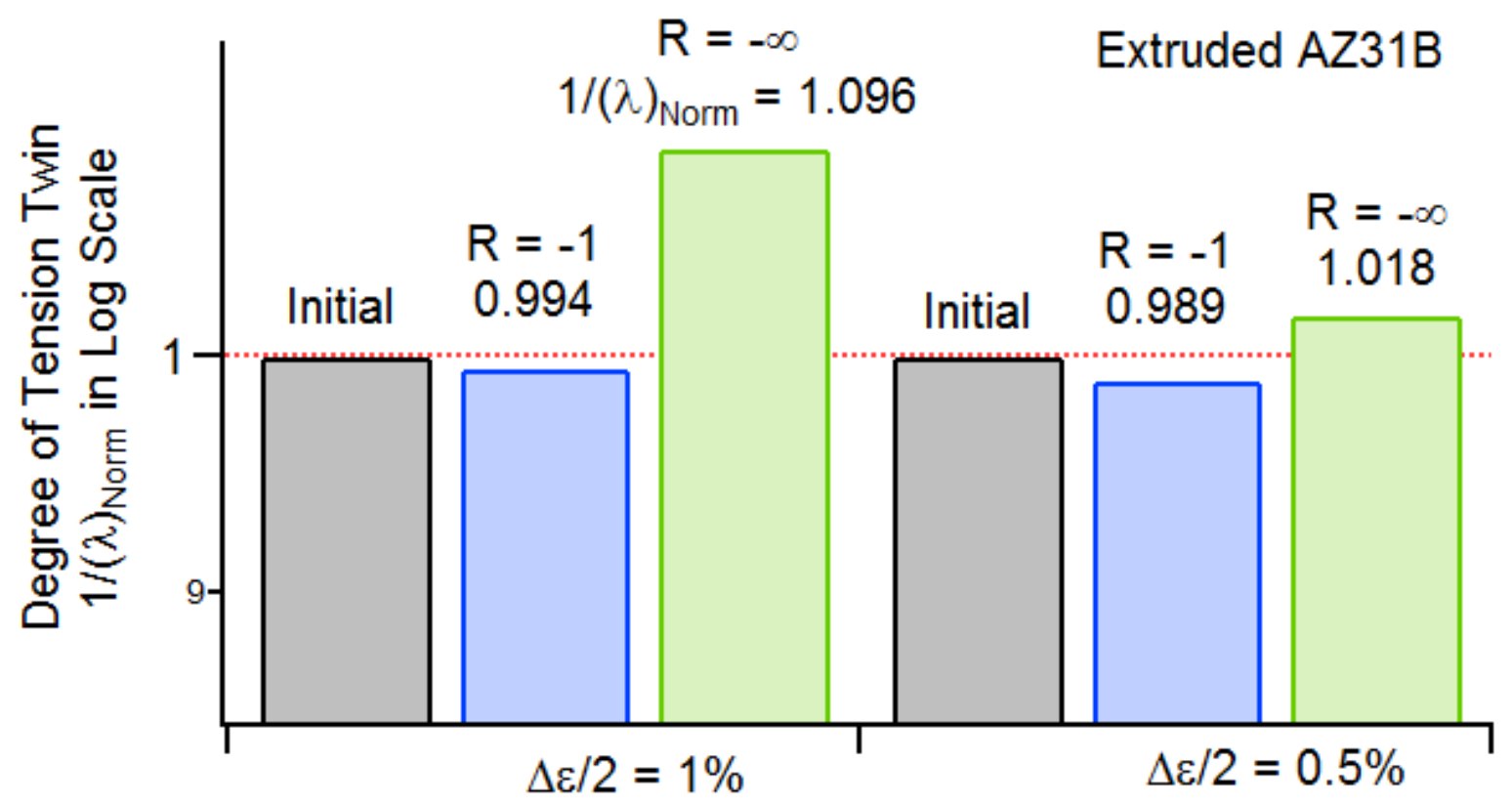

Fig. 5. Degree of residual tension twins after fatigue failure as displayed in Fig. 3.

In order to assess the degree of residual twins in the fatigue-failed samples, X-ray diffraction (XRD) patterns collected from the specimens with different strain ratios $\left(R_{\varepsilon}=-1\right.$ and $\left.-\infty\right)$ are compared at two strain amplitudes, $1 \%$ and $0.5 \%$ (Fig. 4). XRD patterns were acquired from scanning the ED-ND plane that was a few millimeters away from the fracture surface after fatigue. The degree of twinning can be represented by the inverse value of $\lambda=\frac{I_{(0002)}}{I_{(0002)}+I_{(10 \overline{1} 0)}}$ using the integrated intensity of $\{10 \overline{1} 0\}$ and (0002) peaks [24]. The parameter $\lambda$ of the fatigue-failed samples is further normalized by the $\lambda$-value of the initial material, and the normalized $\lambda$ value is denoted by $\lambda_{\text {Norm }}$. As no tension twins were detected in the initial material (Fig. 2), a $1 / \lambda_{\text {Norm }}$ value higher than a unity qualitatively signifies the existence of $\{10-12\}$ tension twins in the sample. Furthermore, a higher value of $1 / \lambda_{\text {Norm }}(>1)$ indicates a higher degree of tension twins remained in the sample. Fig. 5 presents the calculated values of $1 / \lambda_{\text {Norm }}$ for all the fatigue-failed specimens in Fig. 4 . It can been seen that the specimens tested with $R_{\varepsilon}=-1$ displays a $1 / \lambda_{\text {Norm }}$ value very close to unity, indicating insignificant twins left in the fatigued sample. This experimental result is reasonable since there is almost no accumulation of twins due to "partial twinning-complete detwinning" operated during each loading cycle at $R_{\varepsilon}=-1$. In the case of 
$R_{\varepsilon}=-\infty$, both specimens tested at strain amplitudes of $1 \%$ and $0.5 \%$ show $1 / \lambda_{\text {Norm }}$ values larger than unity. More interestingly, the $1 / \lambda_{\text {Norm }}$ value (1.096) of the specimen tested at $\Delta \varepsilon / 2=1 \%$ is larger than that (1.018) in the specimen at $\Delta \varepsilon / 2=0.5 \%$. This result is consistent with the analysis of the stress-strain hysteresis loops in Fig. 3. The $1 / \lambda_{\text {Norm }}$ values for $R_{\varepsilon}=-\infty$ provide a direct evidence confirming that tension twins are accumulated during cyclic deformation with $R_{\varepsilon}=-\infty$ due to "partial twinning-partial detwinning." The remaining amount of tension twins is dependent on the magnitude of the strain amplitude applied.

Plots in Fig. 6 show the variations of the maximum (tensile peak) and minimum (compressive peak) stresses with respect to the increasing number of loading cycles at three strain ratios. At $R_{\varepsilon}=-1$ (Fig. 6a), both the tensile and compressive stress amplitudes evidently increase with the number of loading cycles at strain amplitudes ranging from $0.35 \%$ to $1 \%$, displaying continuous cyclic hardening. Tension-compression asymmetry can be identified due to different tensile and compressive peak stresses. When the strain amplitudes are lower than $0.35 \%$, the maximum and minimum stresses are almost equal and remain approximately unchanged with increasing loading cycles, indicating insignificant cyclic hardening. When the strain amplitudes are between $1 \%$ and $2 \%$, the increasing degree of compressive stress amplitude is higher than that of tensile stress amplitude. It is noticed that at a strain amplitude of $2 \%$, the tensile peak stress decreases with the increasing number of loading cycles. This can be attributed to the microcracks that might be initiated early during the fatigue lives [49]. In the case of $R_{\varepsilon}=0$ (Fig. 6b) at all strain amplitudes smaller than $1.5 \%$, both the maximum and minimum stress amplitudes show a decreasing trend with the increasing of loading cycles. It is noticed that the decreasing degree of the compressive stress amplitude is higher than that of tensile stress amplitude. Such a phenomenon is possibly due to the combined effect of stress relaxation and cyclic hardening [34]. When the strain amplitude is $1.5 \%$, the tensile peak stress decreases significantly as the loading cycle is increased. With $R_{\varepsilon}=-\infty$ (Fig. 6c), at each strain amplitude, the tensile stress amplitude increases significantly whereas the compressive stress amplitude maintains nearly constant. A higher strain amplitude corresponds to a higher increasing rate of the tensile stress amplitude. Such a rapid increase in tensile stress amplitude at higher strain amplitude results in the transformation of the shape of the tensile reversal from concave-down to sigmoidal as the loading cycle increases. 

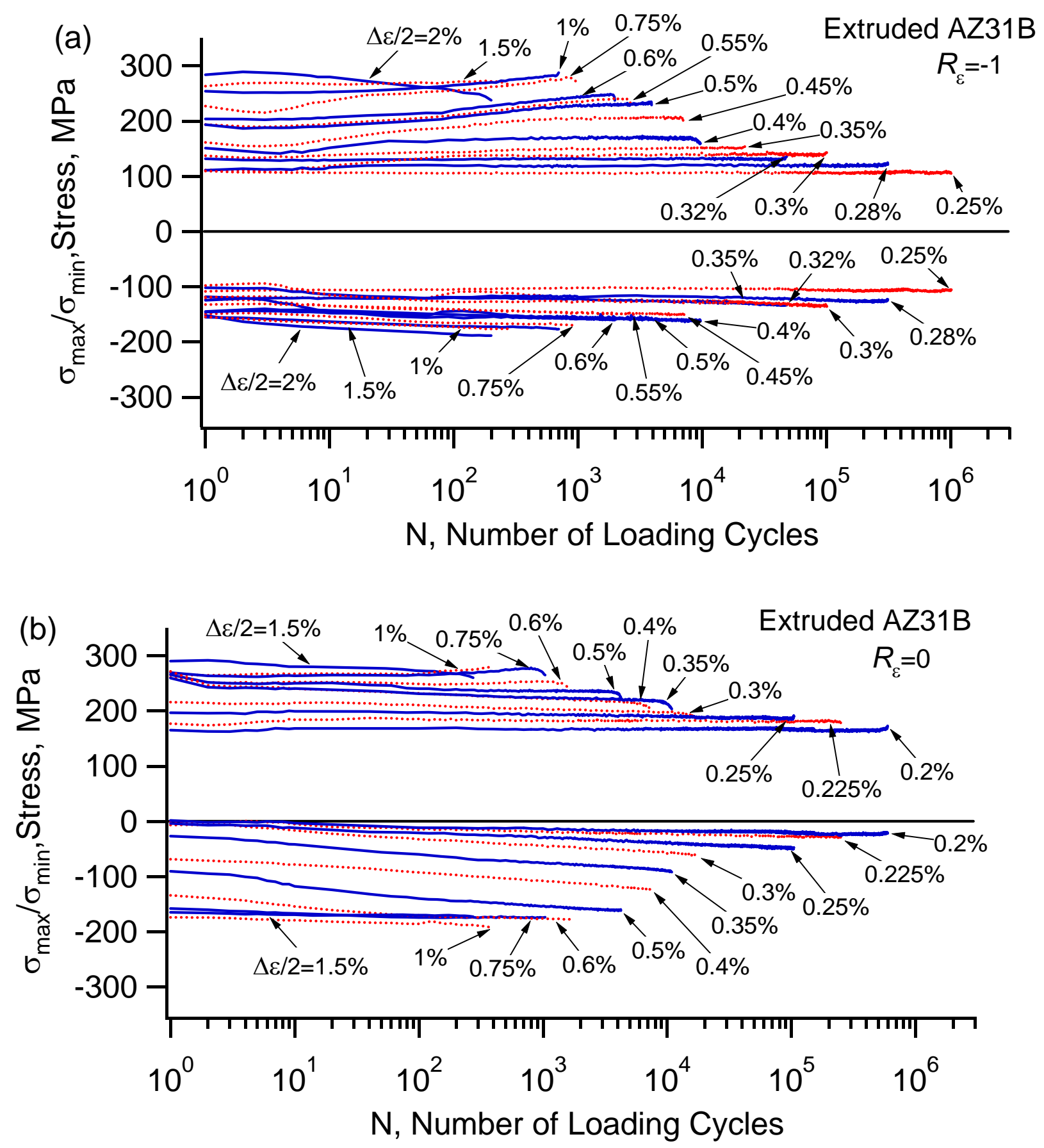


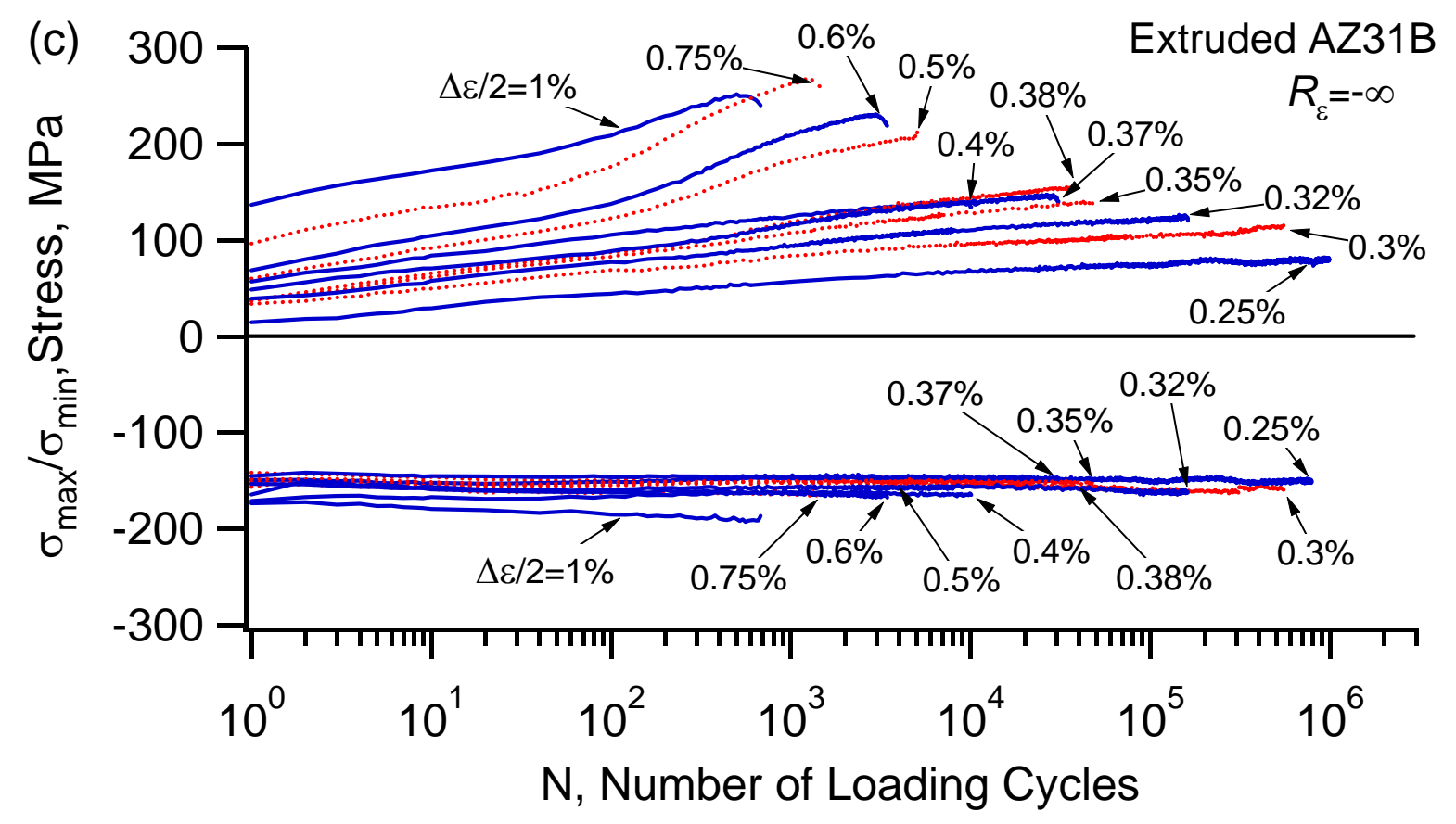

Fig. 6. Variation of maximum and minimum stresses with the number of loading cycles at different strain amplitudes with strain ratios: (a) $R_{\varepsilon}=-1$, (b) $R_{\varepsilon}=0$ and (c) $R_{\varepsilon}=-\infty$.

\subsection{Stabilized hysteresis loops and mean stress}

Fig. 7 shows the stabilized stress-strain hysteresis loops at half-fatigue lives under different strain amplitudes with three strain ratios. Fig. 8 presents the relationship between the strain amplitude and the mean stress. It is found that the shape of the stabilized stress-strain hysteresis loop is dependent mainly on the magnitude of strain amplitude and strain ratio. At $R_{\varepsilon}=-1$, the hysteresis loops are almost symmetrical in the shape (Fig. 7a) and the mean stress (Fig. 8) is nearly zero when the strain amplitude is lower than $0.35 \%$. When the strain amplitude increases from $0.35 \%$ to $1 \%$, the shape of hysteresis loops gradually become asymmetrical and the mean stresses increases from $0 \mathrm{MPa}$ to approximately $52 \mathrm{MPa}$. When the strain amplitude is higher than $1 \%$, the mean stress decreases with increasing strain amplitude, and the mean stress drops to about 34 $\mathrm{MPa}$ at the highest strain amplitude of $2 \%$. 

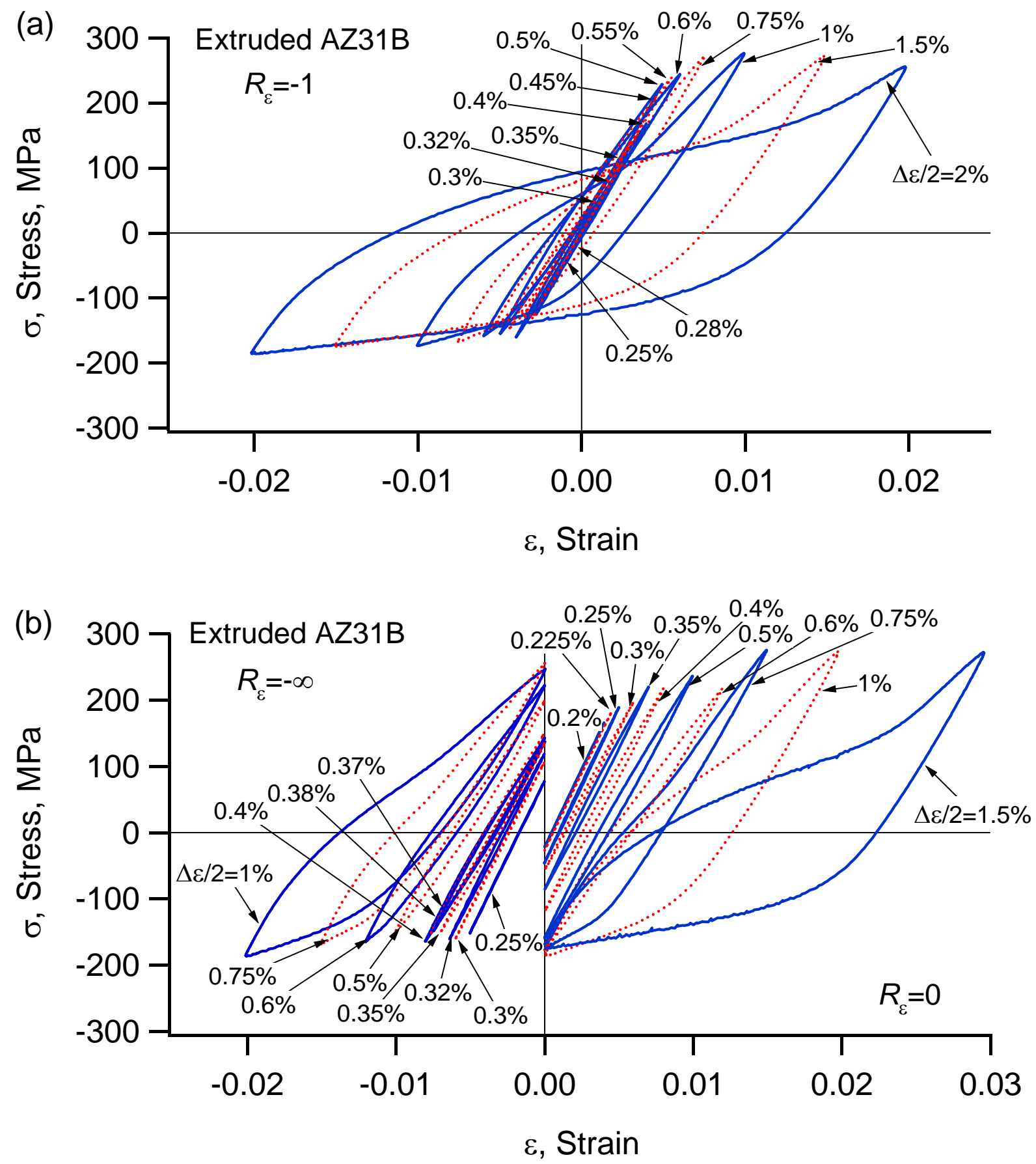

Fig. 7. Stabilized hysteresis loops for different strain ratio: (a) $R_{\varepsilon}=-1$, (b) $R_{\varepsilon}=0$ and $R_{\varepsilon}=-\infty$. 


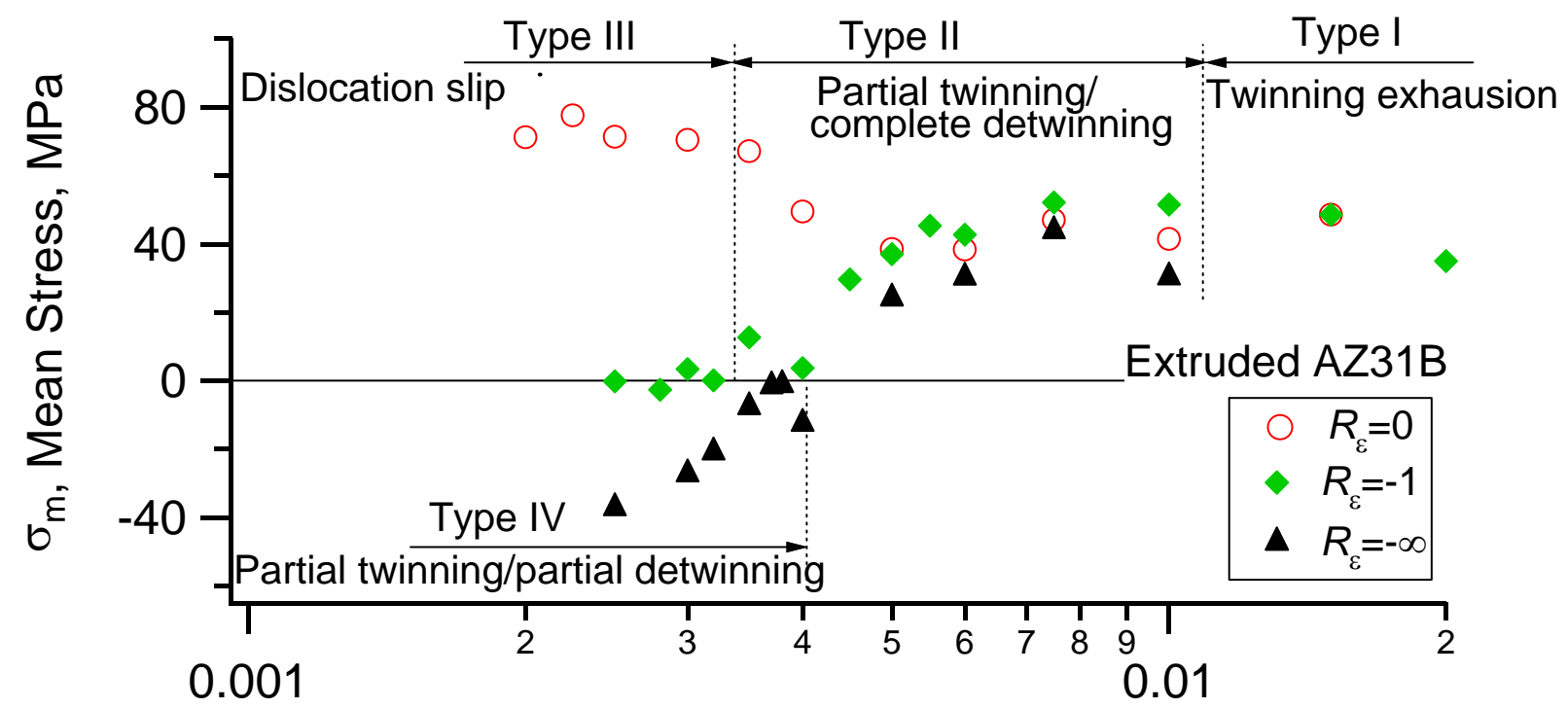

\section{$\Delta \varepsilon / 2$, Strain Amplitude}

Fig. 8. Variations of mean stress with strain amplitude

With $R_{\varepsilon}=0$ and $R_{\varepsilon}=-\infty$, the stress-strain hysteresis loops exhibit an asymmetrical shape when strain amplitude is higher than $0.35 \%$ (Fig. 7b). However, it is clearly from Fig. 8 that the variation of the mean stress with the strain amplitude is different. The mean stress at $R_{\varepsilon}=0$ is tensile, showing a decreasing trend when strain amplitude is lower than $0.5 \%$ and an increasing tendency with increasing strain amplitude from $0.5 \%$ to $1 \%$. When the strain amplitude is higher than $1 \%$, the mean stress decreases again. The mean stress at $R_{\varepsilon}=-\infty$ increases progressively in the range of strain amplitudes lower than $0.75 \%$, and changes from compressive to tensile at a strain amplitude of $0.5 \%$. The tensile mean stress drops when the strain amplitude is higher than $0.75 \%$.

The microscopic mechanisms underlying the stabilized cyclic deformation at different strain amplitude regions and different strain ratios are marked in Fig. 8. Twinning exhaustion appears at strain amplitudes higher than $1 \%$ with $R_{\varepsilon}=-1$ [43]. When the strain amplitude is between $0.35 \%$ and $1 \%$ at different strain ratios, partial twinning-complete detwinning dominates the cyclic plastic deformation. When the strain amplitude is lower than approximately $0.35 \%$, the dominant deformation mechanism is dislocation slips at $R_{\varepsilon}=0$ and $R_{\varepsilon}=-1$. Partial twinning/partial detwinning dominates the cyclic plastic deformation at $R_{\varepsilon}=-\infty$ at strain amplitude less than $0.5 \%$. It should be noticed that mechanisms depicted in Fig. 8 is associated with the stabilized stage of cyclic deformation. 


\subsection{Fatigue fracture profiles}

Fig. 9 shows the three dimensional profiles of fractured specimens under three loading conditions: $R_{\varepsilon}=-1$ and $\Delta \varepsilon / 2=1 \%, R_{\varepsilon}=-1$ and $\Delta \varepsilon / 2=0.5 \%$, and $R_{\varepsilon}=-\infty$ and $\Delta \varepsilon / 2=0.5 \%$. All the fracture surfaces in Fig. 9 share a common fatigue process. At the early stage of crack growth (Region A as circumscribed by the white dotted line), the fatigue crack develops in a tensile mode with the propagation surface perpendicular to the loading direction. Subsequently, the fatigue crack propagates in shear and forms two approximately symmetric propagating surfaces (Region B as denoted within the yellow dotted lines). The final stage is rapid fracture (Region C as denoted within the red dotted lines).
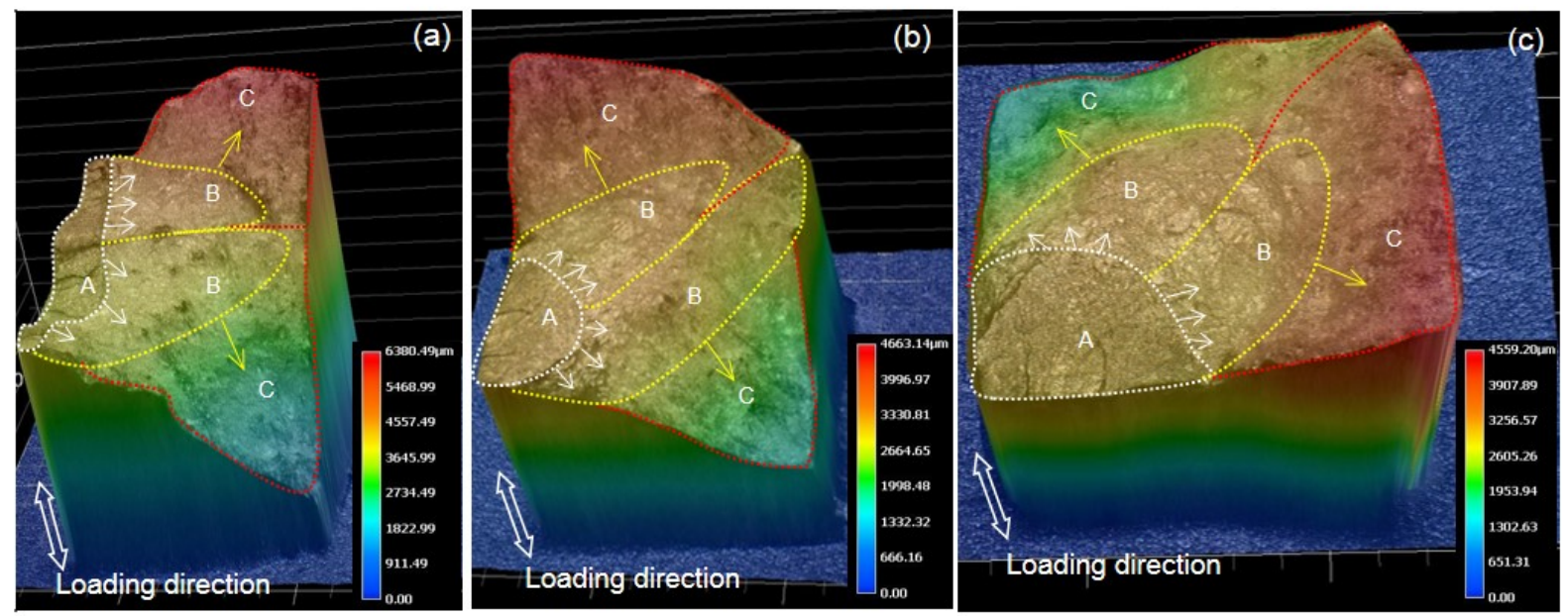

Fig. 9. Surface morphology of fatigue fracture under different strain ratios and strain amplitudes: (a) $R_{\varepsilon}=-1, \Delta \varepsilon / 2=1 \%$, (b) $R_{\varepsilon}=-1, \Delta \varepsilon / 2=0.5 \%$ and (c) $R_{\varepsilon}=-\infty, \Delta \varepsilon / 2=0.5 \%$.

Fig. 10 shows the SEM examination of different regions on the fracture surfaces tested in the same loading conditions as shown in Fig. 9. Figs. 10a, 10d and 10g present low-magnified SEM images of the fracture surfaces resulted from cyclic deformations with the following three loading conditions: $R_{\varepsilon}=-1$ and $\Delta \varepsilon / 2=1 \%, R_{\varepsilon}=-1$ and $\Delta \varepsilon / 2=0.5 \%$, and $R_{\varepsilon}=-\infty$ and $\Delta \varepsilon / 2=0.5 \%$. The fracture surface can be divided into three distinct regions: crack initiation and early crack growth (marked with Region A), crack propagation (marked with Region B), and final rapid fracture region (marked with Region C). Multiple crack initiation sites (white arrows in Figs. 10a, $10 \mathrm{~d}$ and $10 \mathrm{~g}$ ) are found on the specimen surface in all specimens regardless of the applied strain amplitudes and the strain ratios. Several river-pattern like stripes extended from the crack origins exist in Region A. Comparing to the strain amplitude of 1\% (Fig. 10a), fewer crack initiation sites are found at lower strain amplitude of $0.5 \%$. This indicates that a greater amount of microcracks at higher strain amplitudes are initiated and can coalesce to form a macro crack. 

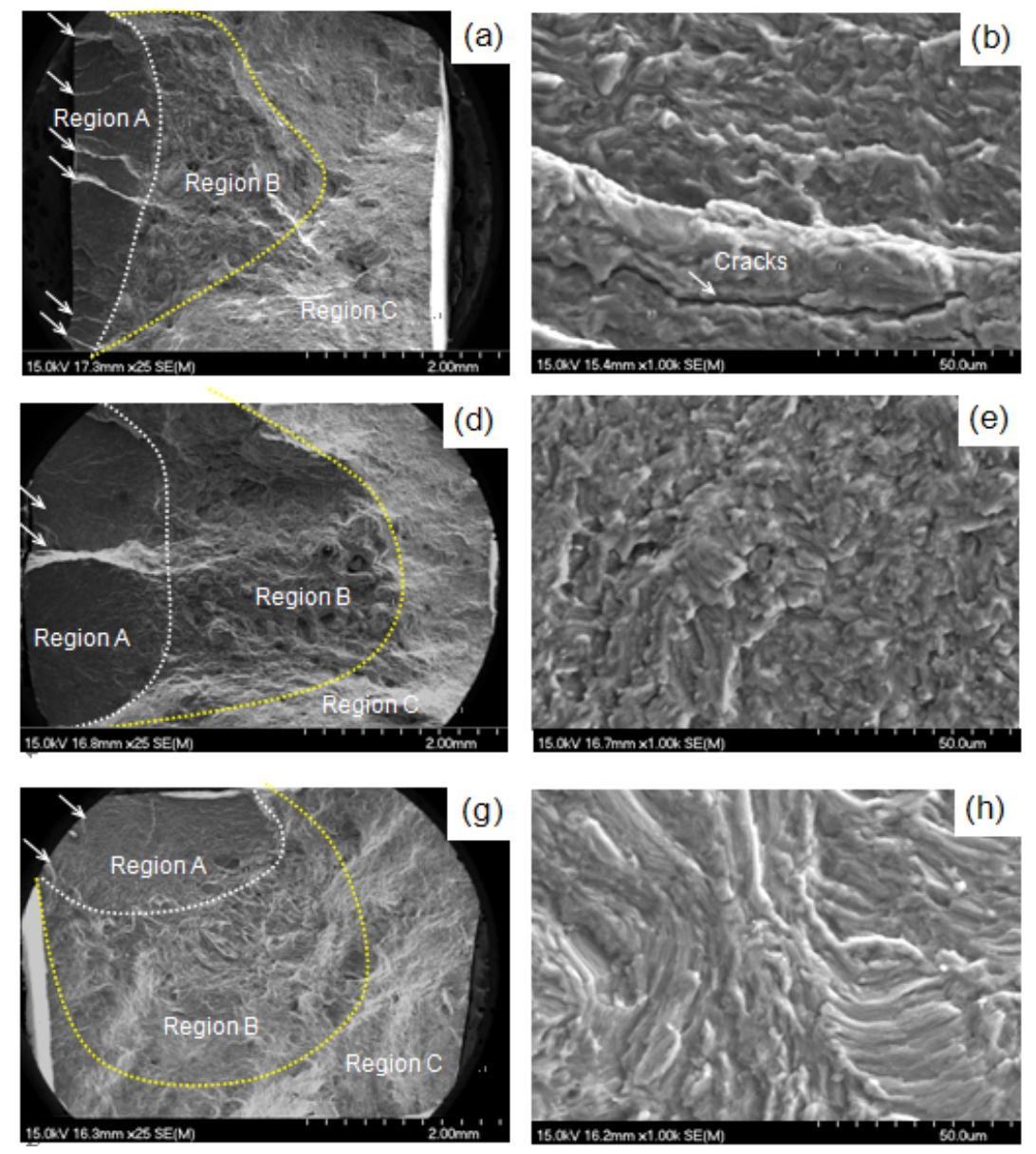
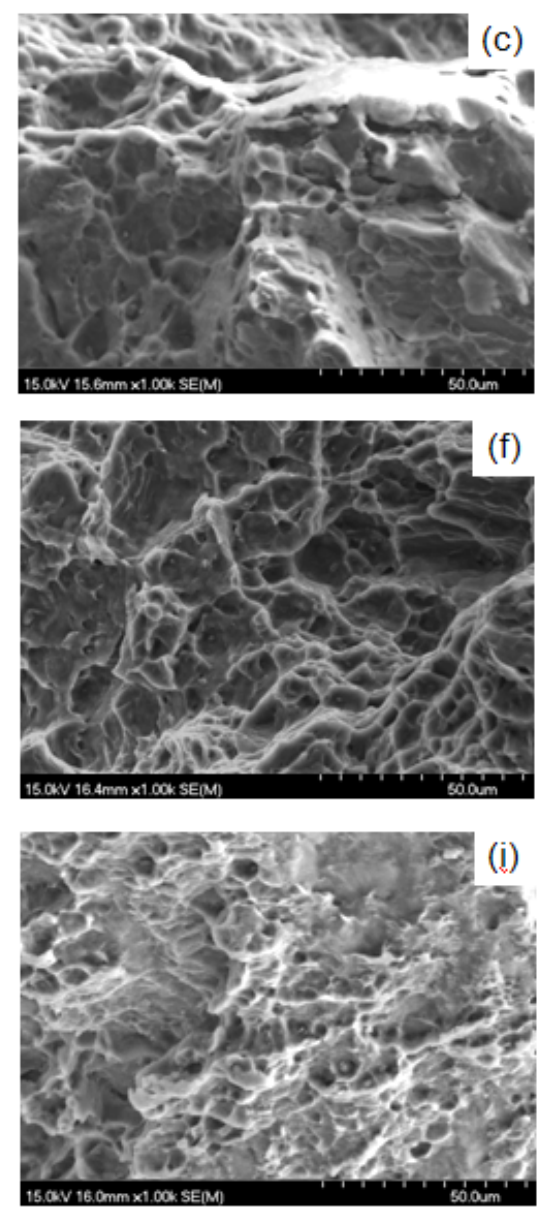

Fig. 10. SEM micrographs of fatigue fracture surface at different strain ratios and strain amplitudes: (a) (c) $R_{\varepsilon}=-1, \Delta \varepsilon / 2=1 \%$, (d) (f) $R_{\varepsilon}=-1, \Delta \varepsilon / 2=0.5 \%$, (g) (i) $R_{\varepsilon}=-\infty, \Delta \varepsilon / 2=0.5 \%$.

Figs. 10b, 10e and 10h show high-magnified SEM micrographs taken in Region A near the crack initiation site. The fatigue crack propagation regions are characterized by transgranular cracking with a cleavage feature. With $R_{\varepsilon}=-1$ at the strain amplitude of $1 \%$ and $0.5 \%$, lamellarfeatured striations can be observed (Fig. 10b). The formation of the fatigue striations in the $\mathrm{Mg}$ alloy is anticipated to be associated with twinning in the compressive phase and detwinning in the tensile phase $[2,4,8,35,40-41,50-51]$. In addition, some secondary cracks oriented along the direction of the striation development can be observed at a strain amplitude of $1 \%$. Similar observations were reported in the extruded Mg alloys [4,8,9,35]. When the strain amplitude is decreased to $0.5 \%$ (Fig. 10e), the lamellar-like traces become mitigated. In contrast, flake-like surfaces appear in the stable crack propagation region. Such a feature might be resulted from the twinning-detwinning process together with the repeated blunting-sharpening process due to dislocation slips in the plastic zone ahead of the fatigue crack tip [52]. With decreasing strain 
ratio to $R_{\varepsilon}=-\infty$ at a strain amplitude of $0.5 \%$, the lamellar-like traces are aggravated, as clearly shown in Fig. 10h. The increased lamellar-like traces can be associated with the accumulated twins in the material resulted from the repeated partial twinning-partial detwinning process operated in particular at $R_{\varepsilon}=-\infty$. High-magnified SEM micrographs taken in Region C as shown in Figs. 10c, 10f and 10i correspond to macro crack propagation. Final fracture regions have intergranular dimple-like features, which is typical for ductile metallic materials fractured under monotonic tension.

\subsection{Fatigue life and fatigue criterion}

The strain-life fatigue curves with three different strain ratios are shown in Fig. 11. The following three-parameter equation is used to describe the strain-life curves by fitting the experimental data,

$$
\left(\left(\frac{\Delta \varepsilon}{2}\right)-\varepsilon_{0}\right)^{\xi} N_{f}=C
$$

where $\Delta \varepsilon / 2$ is the strain amplitude and $N_{\mathrm{f}}$ is the number of loading cycles to failure. The remaining three symbols, $\varepsilon_{0}$, $\xi$, and $C$, are the constants identified by best fitting the experimental data. It is clearly indicated that a single Eq. (1) cannot well describe the whole strain-life curve. A distinguishable kink in each strain-life curve can be identified for a specific $R$-ratio. Similar phenomena were reported for other wrought $\mathrm{Mg}$ alloys [22,30-31,34,42,44-45]. The strain amplitudes corresponding to the kink points are $0.4 \%$ for $R_{\varepsilon}=-\infty, 0.45 \%$ for $R_{\varepsilon}=-1$, and $0.5 \%$ for $R_{\varepsilon}=0$. The fatigue lives corresponding to the kink points are approximately 25,700 cycles at $R_{\varepsilon}=-\infty, 7,000$ cycles at $R_{\varepsilon}=-1$, and 4,200 cycles at $R_{\varepsilon}=0$. With an identical strain amplitude, fatigue life with $R_{\varepsilon}=-\infty$ shows the highest. As discussed in the previous section, the two strain amplitude regions above or below the kink point are related to different cyclic deformation behavior and mean stress effects. For $R_{\varepsilon}=-1$ and 0 , partial (or exhausted) twinning-complete detwinning dominates the strain amplitude region above the kink point whereas dislocation slips dominate the strain amplitude region below the kink point. For $R_{\varepsilon}=-\infty$, the kink point potentially demarcates two strain amplitude regions: when the strain amplitude is above the kink point, partial twinning-partial detwinning during the initial stage of cyclic deformation transits to partial twinning-complete detwinning during the later stage. When the strain amplitude is below the kink point, partial twinning-partial detwinning plays a major role throughout the cyclic deformation process. 


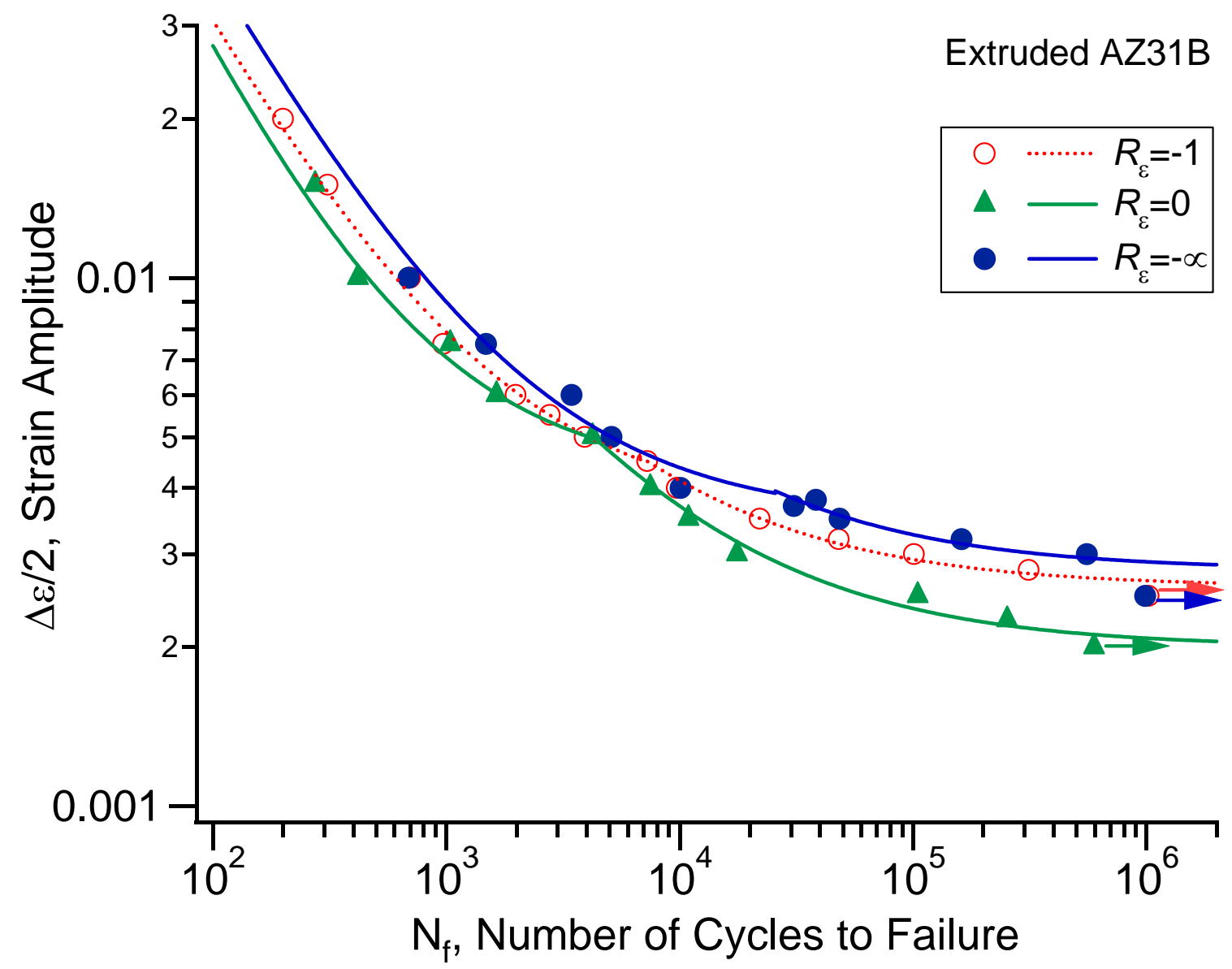

Fig. 11. Strain-life curves under different loading conditions

The Smith, Watson, and Topper (SWT) fatigue model [53] is an energy-based fatigue criterion. It was originally developed to consider the growth of microcracks in tensile cracking under uniaxial loading. The SWT model can be expresses as:

$$
S W T=\frac{\Delta \varepsilon}{2}\left\langle\sigma_{\max }\right\rangle
$$

where $\Delta \varepsilon / 2$ is the strain amplitude and $\sigma_{\max }$ is the maximum stress in a loading cycle. The symbols \langle\rangle are the MacCauley brackets with the definition $\langle x\rangle=0.5(x+|x|)$. SWT denotes the SWT parameter. Fig. 12 shows the relationship between the fatigue parameter SWT and fatigue life for all the specimens tested. The solid line is an approximate medium line of all the test specimens, and the two dotted lines are the factor-of-two boundaries. Most data points fall within the factor-of-two lines. This suggests that the SWT parameter correlates well the uniaxial tension-compression fatigue experiments of the AZ31B alloy with different strain ratios. The SWT parameter is also found to correlate well for ZK60 and AZ61 Mg alloy under uniaxial loading 
condition $[34,42]$.

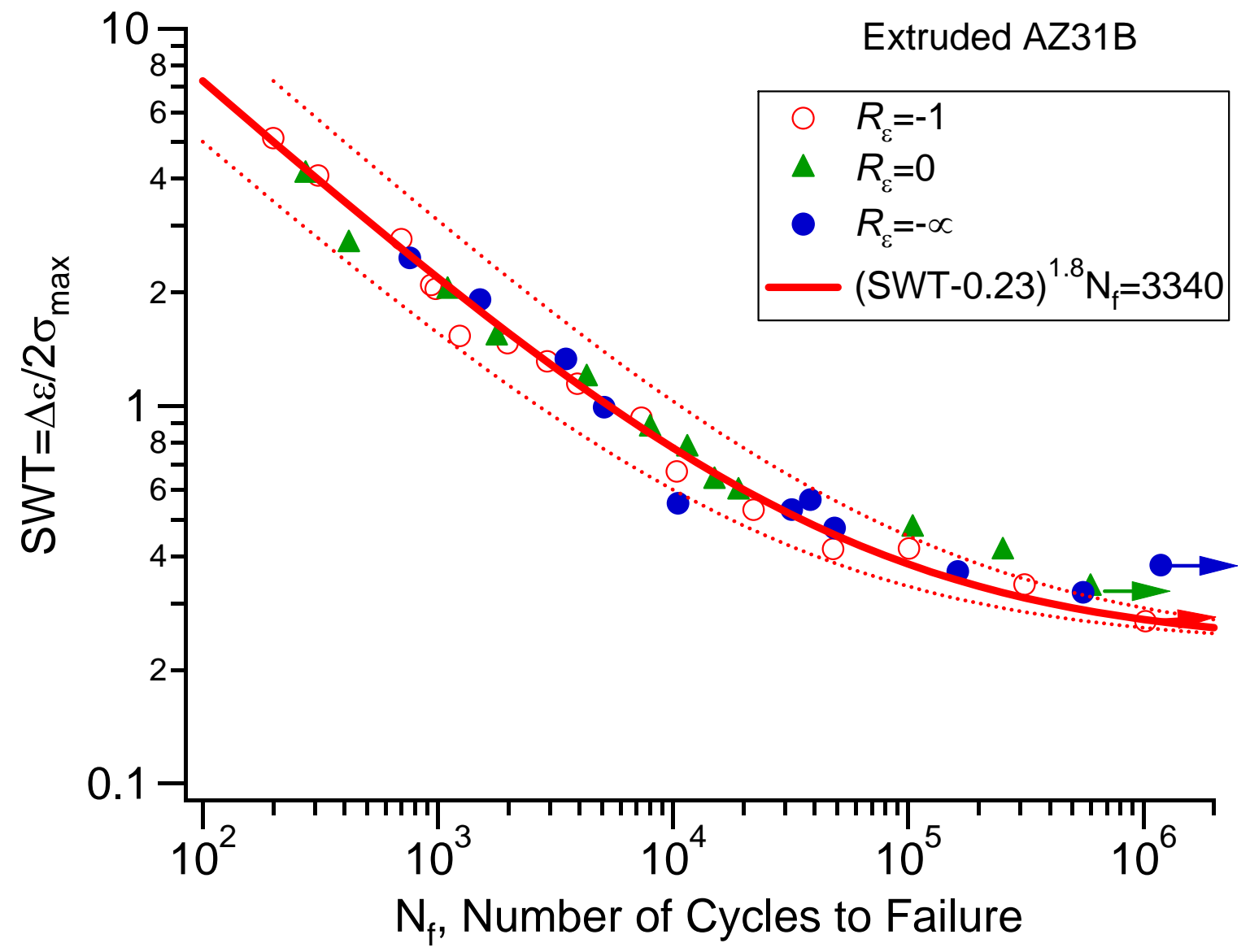

Fig. 12. SWT parameter versus fatigue lives for three strain ratios.

\section{Further discussion}

$\mathrm{AZ31B}$ and AZ61A belong to the AZ-series Mg alloys, and the strain ratio effect is similar for both materials under uniaxial loading. However, the fatigue life of AZ31B Mg alloy is higher than that of AZ61A Mg alloy under the same uniaxial loading conditions [22,34]. The reason might lies in the different fatigue damage processes rooted in the different microstructures between AZ31B Mg alloy and AZ61 A Mg alloy. The original microstructures of AZ31B Mg alloy shows a non-uniform grain structure containing both the elongated grains and the small equiaxed grains (see Fig. 2a). AZ61A Mg alloy has an equiaxed grain structure with an average grain size of approximate $20 \mu \mathrm{m}$ [30]. Figs. 13a and 13b show the optical microscope (OM) and SEM microscopic observations of fatigue tested specimen at 424 cycles at a strain amplitude of $1 \%$ with $R_{\varepsilon}=-1$ for AZ31B Mg alloy. Deformation twins are observed in larger grains (Fig. 13a). It is revealed that most fatigue cracks appear along the boundaries of the small grain clusters (Fig. 13b). Crack propagation is very limited since crack growth is often arrested at either the grain boundary 
or within the interior of the neighboring grains (Fig. 13b). Noting that the current AZ31B Mg alloy has an inhomogeneous grain structure and deformation twins are mostly formed in the large elongated grains rather than small grains, it can be derived that the observed crack propagation paths arrested within the small grains are most likely caused by alternative dislocation slipping mechanism instead of twin boundary cracking. In contrast, AZ61A Mg alloy possesses a homogeneous grain structure [31,34]. Intergranular microcracks usually have longer segments than those exhibited in AZ31B Mg alloy. Furthermore, due to the larger grain size in AZ61 A Mg alloy, deformation twin can be easily produced in the region ahead of crack propagation path. Accordingly, transgranular propagation in AZ61 A Mg alloy can be found on the crack growth path not only due to dislocation slips but also along twin boundaries. This suggests that transgranular crack propagation is easier in the homogenous grain structure of AZ61 A Mg alloy than that in the inhomogeneous grain structure of AZ31B Mg alloy. In brief, resistance of fatigue cracking in a uniform equiaxed grain structure of AZ61A is weaker than that in a non-uniform fibrous grain structure of AZ31B, resulting in a shorter fatigue life of AZ61A than that of AZ31B at an identical strain amplitude.
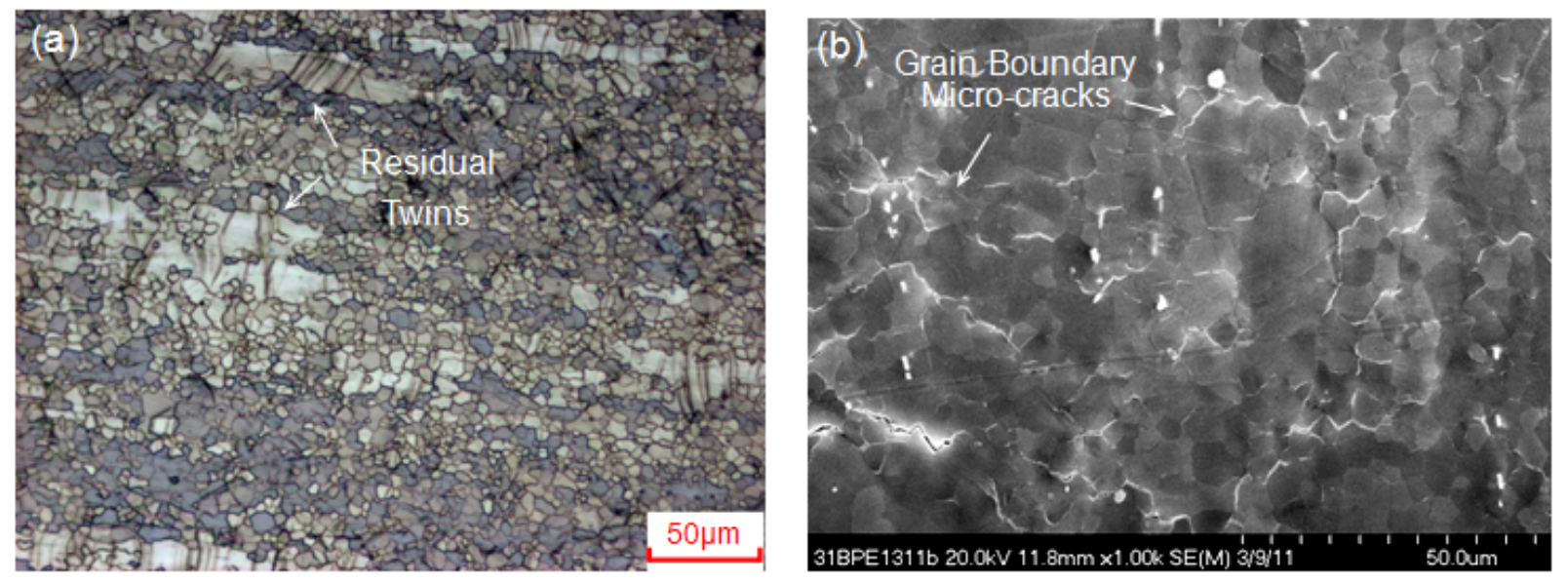

Fig. 13. Mmicrostructure of AZ31B interrupted at the $424^{\text {th }}$ loading cycle at strain amplitude of $1 \%$ with $R_{\varepsilon}=-1$ (a) OM; (b) SEM.

\section{Conclusions}

The cyclic deformation and fatigue behavior of extruded AZ31B Mg alloy were experimentally investigated at different strain amplitudes with three strain ratios. Key findings are summarized as follows:

(1) The stress-strain hysteresis loops exhibit an asymmetric shape when the strain amplitude is larger than $0.5 \%$ with $R_{\varepsilon}=-\infty$ and $0.35 \%$ with $R_{\varepsilon}=0$ and $R_{\varepsilon}=-1$.

(2) For $R_{\varepsilon}=0$ and $R_{\varepsilon}=-1$, partial twinning-complete detwinning dominates cyclic plastic deformation at strain amplitudes between $0.35 \%$ and $1 \%$. When strain amplitude is lower than 
$0.35 \%$, dominant deformation mechanism is dislocation slips. For $R_{\varepsilon}=-\infty$, partial twinningpartial detwinning dominates the whole stage of cyclic plastic deformation when strain amplitude is less than $0.5 \%$. When strain amplitude is higher than $0.5 \%$, cyclic deformation transits from partial twinning-partial detwinning in the initial stage to partial twinningcomplete detwinning in the later stage.

(3) Comparing the case of $R_{\varepsilon}=0$ with that of $R_{\varepsilon}=-1$, stronger cyclic hardening is found in $R_{\varepsilon}=-\infty$ at all the strain amplitudes tested.

(4) Fatigue crack is initiated from the specimen surface. A higher strain amplitude results in a higher number of crack initiation sites. Crack propagation can be divided into early crack growth and stable crack growth, where lamellar-like and dimple-like features are exhibited, respectively. At the same strain amplitude, the lamellar-like traces during early crack growth become more obvious at a lower strain ratio.

(5) The strain-life fatigue curve exhibits a distinguishable kink for each strain ratio. At an identical strain amplitude, fatigue life with $R_{\varepsilon}=-\infty$ shows the highest and that with $R_{\varepsilon}=0$ is the lowest.

(6) The Smith, Watson, and Topper (SWT) fatigue model correlates well the uniaxial tensioncompression fatigue experiments of AZ31B Mg alloy at different strain ratios.

Acknowledgement:

Ying Xiong gratefully acknowledges financial supports provided by the Natural Science Foundation of China (No. 51275472) and the Natural Science Foundation of Zhejiang Province (No. LY12E05024). Yanyao Jiang thanks support from the National Science Foundation (CMMI-1462885).

\section{References}

[1] Hasegawa S, Tsuchida Y, Yano H, Matsui M. Evaluation of low cycle fatigue life in AZ31 magnesium alloy. Int J Fatigue 2007; 29: 1839-1845.

[2] Brown DW, Jain A, Agnew SR, Clausen B. Twinning and detwinning during cyclic deformation of Mg alloy AZ31B. Mater Sci Forum. 2007; 539-543: 3407-3413.

[3] Ishihara $S$, Nan Z, Goshima T. Effect of microstructure on fatigue behavior of AZ31 magnesium alloy. Mater Sci Eng A. 2007; 468-470: 214-222.

[4] Lin XZ, Chen DL. Strain controlled cyclic deformation behavior of an extruded magnesium alloy. Mater Sci Eng A. 2008; 496: 106-113.

[5] Yang F, Yin SM, Li SX, Zhang ZF. Crack initiation mechanism of extruded AZ31 magnesium alloy in the very high cycle fatigue regime. Mater Sci Eng A. 2008; 491: 131136.

[6] Yin SM, Yang HJ, Li SX, Wu SD, Yang F. Cyclic deformation behavior of as-extruded Mg- 
3\%Al-1\%Zn. Scr Mater. 2008; 58: 751-754.

[7] Yin SM, Yang F, Yang XM, Wu SD, Li SX., Li GY. The role of twinning-detwinning on fatigue fracture morphology of Mg-3\%Al-1\%Zn alloy. Mater Sci Eng A. 2008; 494: 397400.

[8] Begum S, Chen DL, Xu S, Luo AA. Low cycle fatigue properties of an extruded AZ31 magnesium alloy. Int J Fatigue 2009; 31: 726-735.

[9] Begum S, Chen DL, Xu S, Luo AA. Effect of strain ratio and strain rate on low cyclic fatigue behavior of AZ31wrought magnesium alloy. Mater Sci Eng A. 2009; 517: 334-343.

[10] Nascimento L, Yi S, Bohlen J, Fuskova L, Letzig D, Kainer KU. High Cycle Fatigue Behaviour of Magnesium Alloys. Procedia Engineering 2009; 2: 743-750.

[11] Matsuzuki M, Horibe S. Analysis of fatigue damage process in magnesium alloy AZ31. Mater Sci Eng A. 2009; 504: 169-174.

[12] Huppmann, M., Lentz, M., Brömmelhoff K, Reimers W. Fatigue properties of the hot extruded magnesium alloy AZ31. Mater Sci Eng A. 2010; 527: 5514-5521.

[13] Wu YJ, Zhu R, Wang JT, Ji WQ. Role of twinning and slip in cyclic deformation of extruded Mg-3\%Al-1\%Zn alloys. Scr Mater. 2010; 63: 1077-1080.

[14] Huppmann M, Lentz M, Chedid S, Reimers W. Analyses of deformation twinning in the extruded magnesium alloy AZ31 after compressive and cyclic loading. J Mater Sci. 2011; 46: 938-950.

[15] Kwon SH, Song KS, Shin KS, Kwun SI. Low cycle fatigue properties and an energy-based approach for as-extruded AZ31 magnesium Alloy. Met Mater. 2011; 17: 207-213.

[16] Lv F, Yang YS, Li SX, Zhang ZF. Effects of hysteresis energy and mean stress on low-cycle fatigue behaviors of an extruded magnesium alloy. Scr Mater. 2011; 65: 53-56.

[17] Albinmousa J, Jahed H, Lambert S. Cyclic behaviour of wrought magnesium alloy under multiaxial load. Int J Fatigue 2011; 33: 1127-1139.

[18] Albinmousa J, Jahed H, Lambert S. a. Cyclic axial and cyclic torsional behaviour of extruded AZ31B magnesium alloy. Int. J. Fatigue 2011; 33: 1403-1416.

[19] Zhang XP, Castagne S, Gu CF, Luo XF. Effects of annealing treatment on the ratcheting behavior of extruded AZ31B magnesium alloy under asymmetrical uniaxial cyclic loading. $J$ Mater Sci. 2011; 46: 1124-1131.

[20] Zhang XP, Castagne S, Luo XF, Gu CF. Effects of extrusion ratio on the ratcheting behavior of extruded AZ31B magnesium alloy under asymmetrical uniaxial cyclic loading. Mater. Sci Eng A. 2011; 528: 838-45.

[21] Chen C, Liu T, Lv C, Lu L, Luo D. Study on cyclic deformation behavior of extruded Mg3Al-1Zn alloy. Mater Sci Eng A. 2012; 539: 223-229.

[22] Xiong Y, Yu Q, Jiang Y. Multiaxial fatigue of extruded AZ31B magnesium alloy. Mater Sci Eng $A$ 2012; 546:119-128.

[23] Geng CJ, Wu BL, Du XH, Wang YD, Zhang YD, Wagner F, Esling C. Low cycle fatigue behavior of the textured AZ31B magnesium alloy under the asymmetrical loading. Mater Sci Eng A. 2013; 560: 618-626.

[24] Ozaki J, Yosida, Horibe S. The effect of pre-compressive strain on the fatigue life of the 
AZ31 magnesium alloy. Mater Sci Eng A 2014; 604:192-195.

[25] Duan GS, Wu BL, Du XH, Zhao X, Zhang YD, Zuo L, Esling C. The cyclic frequency sensitivity of low cycle fatigue (LCF) behavior of the AZ31B magnesium alloy. Mater Sci Eng A. 2014; 603: 11-22.

[26] Kang GZ, Yu C, Liu YJ, Quan GF. Uniaxial ratchetting of extruded AZ31 magnesium alloy: Effect of mean stress. Mater Sci Eng A. 2014; 607: 318-327.

[27] Shih TS, Liu WS, Chen YJ. Fatigue of as-extruded AZ61A magnesium alloy. Mater Sci Eng A. 2002; 325: 152-162.

[28] Sajuri ZB, Miyashita Y, Hosokai Y, Mutoh Y. Effects of Mn content and texture on fatigue properties of as-cast and extruded AZ61 magnesium alloys. Int J Mech Sci. 2006; 48: 198209.

[29] Li Q, Yu Q, Zhang J, Jiang Y. Effect of strain amplitude on tension-compression fatigue behavior of extruded Mg6Al1ZnA magnesium alloy. Scr Mater. 2010; 62: 778-781.

[30] Zhang J, Yu Q, Jiang Y, Li Q. An experimental study of cyclic deformation of extruded AZ61A magnesium alloy. Int J Plasticity 2011; 27:768-787.

[31] Yu, Q, Zhang J, Jiang Y, Li Q. Multiaxial fatigue of extruded AZ61A magnesium alloy. Int J Fatigue 2011; 33: 437-447.

[32] Jordon JB, Gibson JB, Horstemeyer MF, Kadiri HE, Baird JC, Luo AA. Effect of twinning, slip, and inclusions on the fatigue anisotropy of extrusion-textured AZ61 magnesium alloy. Mater Sci Eng A. 2011; 528: 6860-6871.

[33] Li Q, Yu Q, Zhang J, Jiang Y. Microstructure and deformation mechanism of Mg6Al1ZnA alloy experienced tension-compression cyclic loading. Scr Mater. 2011; 64: 233-236.

[34] Yu Q, Zhang J, Jiang Y, Li Q. Effect of strain ratio on cyclic deformation and fatigue of extruded AZ61A magnesium alloy. Int J Fatigue 2012; 44: 225-233.

[35] Begum S, Chen DL, Xu S, Luo Alan A. Strain-controlled low-cycle fatigue properties of a newly developed extruded magnesium alloy. Metall Mater Trans A. 2008; 39: 3014-3026.

[36] Fan, C.L., Chen, D.L., Luo, A.A., Dependence of the distribution of deformation twins on strain amplitudes in an extruded magnesium alloy after cyclic deformation. Mater Sci Eng A. 2009; 519, 38-45.

[37] Luo TJ, Yang YS, Tong WH, Duan QQ, Dong X.G. Fatigue deformation characteristic of asextruded AM30 magnesium alloy. Mater. Des. 2010; 31: 1617-1621.

[38] Jordon JB, Brown HR, Kadiri HE, Kistler HM, Lett RL, Baird JC, Luo AA. Investigation of fatigue anisotropy in an extruded magnesium alloy. Int J Fatigue 2013; 51: 8-14.

[39] Chen L, Wang C, Wu W, Liu Z, Stoica G, Wu L, et al. Low-cycle fatigue behavior of an asextruded AM50 magnesium alloy. Metall Mater Trans A. 2007; 38: 2235-2241.

[40] Wu L, Agnew SR, Brown DW, Stoica GM, Clausen B, Jain A, Fielden DE, Liaw PK. Internal stress relaxation and load redistribution during the twinning-detwinning-dominated cyclic deformation of a wrought magnesium alloy ZK60A. Acta Mater. 2008; 56: 3699-3707.

[41] Wu L, Jain A, Brown DW, Stoica GM, Agnew SR, Clausen B, Fielden DE, Liaw PK. Twinning-detwinning behavior during the strain-controlled low-cycle fatigue testing of a wrought magnesium alloy, ZK60A. Acta Mater. 2008; 56: 688-695. 
[42] Yu Q, Zhang J, Jiang Y, Li Q. An experimental study on cyclic deformation and fatigue of extruded ZK60 magnesium alloy. Int J Fatigue 2012; 36: 47-58.

[43] Xiong Y, Yu Q, Jiang Y. An experimental study of cyclic plastic deformation of extruded ZK60 Magnesium alloy. In J Plasticity 2014; 53:107-124.

[44] Xiong Y, Jiang Y. Fatigue of ZK60 Magnesium alloy under uniaxial loading. Int J Fatigue 2014; 64: 74-83.

[45] Dong S, Yu Q, Jiang Y, Dong J, Wang F, Ding W. Cyclic deformation and fatigue of extruded ZK60 magnesium alloy with aging effects. Mater Sci Eng A. 2014; 615: 262-272.

[46] Dong S, Yu Q, Jiang Y, Dong J, Wang F, Ding W. Electron backscatter diffraction observations of twinning-detwinning evolution in a magnesium alloy subjected to large strain amplitude cyclic loading. Mater. Des. 2015; 65: 762-765.

[47] Hassan HA, Lewandowski JJ. Effects of particulate volume fraction on cyclic stress response and fatigue life of AZ91D magnesium alloy metal matrix composites. Mater Sci Eng A. 2014; 600: 188-194.

[48] $\mathrm{Yu}$ Q, Zhang J, Jiang Y. Direct observation of twinning-detwinning-retwinning on magnesium single crystal subjected to strain-controlled cyclic tension-compression in [0001] direction. Philos Mag Lett. 2011; 91:757-765.

[49] Yu Q, Zhang J, Jiang Y. Fatigue damage development in pure polycrystalline magnesium under cyclic tension-compression loading. Mater Sci Eng A. 2011; 528: 7816-7826.

[50] Wang YN, Huang JC. The role of twinning and untwinning in yielding behavior in hotextruded Mg-Al-Zn alloy. Acta Mater. 2007; 55: 897-905.

[51] Lou XY, Li M, Boger RK, Agnew SR, Wagoner RH. Hardening evolution of AZ31B Mg sheet. Int J Plasticity 2007; 23: 44-86.

[52] Laird C. Fatigue Crack Propagation, ASTM STP 415, 1967, 131-168.

[53] Smith RN, Watson P, Topper TH. A stress-strain parameter for the fatigue of metals. $J$ Mater. 1970; 5: 767-778. 